\title{
Ofrendar y propiciar. Fauna y prácticas agropastoriles prehispánicas del segundo milenio AP en Antofagasta de la Sierra, Puna Meridional Argentina
}

\author{
SILVANA V. URQUIZA \& MARÍA DEL PILAR BABOT \\ Instituto de Arqueología y Museo, Universidad Nacional de Tucumán (IAM, UNT) - Instituto Superior de Estudios \\ Sociales, Consejo Nacional de Investigaciones Científicas y Técnicas (ISES, CONICET/UNT) \\ silvanaurquiza@csnat.unt.edu.ar; pilarbabot@csnat.unt.edu.ar
}

(Recibido 20 septiembre 2017; Revisado 9 febrero 2018; Aceptado 8 marzo 2018)

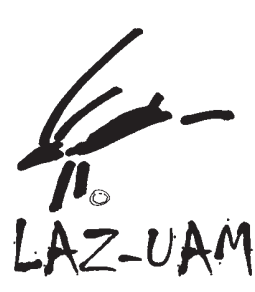

RESUMEN: En esta contribución analizamos conjuntos arqueofaunísticos procedentes de depósitos inferidos como enterramientos intencionales de objetos (en pozos y como acumulaciones). Éstos corresponden a eventos ocurridos en torno a un recinto central del sitio residencial agropastoril Punta de la Peña 9, en Antofagasta de la Sierra, (provincia de Catamarca), Puna meridional argentina, durante el segundo milenio AP (ca. 1516-929 años cal. AP). Realizamos una caracterización de la fauna de vertebrados e invertebrados desde un punto de vista anatómico, taxonómico y tafonómico. El análisis de estos elementos, las recurrencias y ausencias e indicadores de estacionalidad, sumados a la presencia de otros objetos incluidos en los depósitos, su estructuración y cronología relativa a la historia de uso del recinto, son interpretados a la luz de prácticas y relatos tradicionales de los Andes Centro Sur. Esto nos permite postular la ocurrencia de eventos fundacionales y de instancias de propiciación referidas a la estación seca dentro de los ciclos agropastoriles centro-surandinos.

PALABRAS CLAVE: PUNA ARGENTINA, PRÁCTICAS AGROPASTORILES, ZOOARQUEOLOGÍA, DEPÓSITOS RITUALES, SEGUNDO MILENIO AP

\begin{abstract}
In this work we analyze zooarchaeological data from deposits inferred as intentional burials of objects (in pits and as discrete accumulations). These burials are related to events that took place around a central structure in the agro-pastoralist residential site of Punta de la Peña 9 (Antofagasta de la Sierra, Catamarca province, Argentinian Southern Puna) during the second millennium BP ( $c a$. 1516-929 years cal. BP). To elucidate this issue a characterization of the vertebrate and invertebrate faunal remains from an anatomical, taxonomic and taphonomic point of view, is carried out. The analysis of these elements, recurrences and absences and indicators of seasonality, in addition to the presence of other objects within the deposits, their structuring and chronology relative to the history of use of the central structure, are interpreted in the light of traditions of the South-Central Andes. This allows us to propose the occurrence of foundational events and instances of rites associated with the dry season within the south Andean agro-pastoralist cycles.
\end{abstract}

KEYWORDS: ARGENTINE PUNA, AGRO-PASTORALIST PRACTICES, ZOOARCHAEOLOGY, RITUAL CACHES, SECOND MILLENNIUM BP 


\section{INTRODUCCIÓN}

En este trabajo abordamos conjuntos faunísticos procedentes de depósitos intencionales de objetos (Babot et al., 2007) que corresponden a eventos ocurridos $c a$. 1516-929 años cal. AP en torno a un recinto de grandes dimensiones del sitio Punta de la Peña 9, sector I (PP9.I), en Antofagasta de la Sierra, provincia de Catamarca, Argentina (Figura 1). Este sitio constituye uno de los asentamientos residenciales agropastoriles mejor conocidos de la porción meridional de la Puna en territorio argentino, ámbito que se caracteriza por conformar un desierto de altura que se eleva sobre los $3500 \mathrm{msnm}$, dentro de la diagonal árida sudamericana. PP9.I se asocia a sociedades aldeanas productoras del segundo milenio AP que se organizaron en torno al pastoreo de la llama (Lama glama), al igual que otros sitios del área (Urquiza \& Aschero, 2014; Grant \& Escola, 2015, entre otros), lo que las encuadra en un proceso macrorregional que alcanzó a una vasta porción de los Andes Centro Sur (Olivera, 1988; Hocsman \& Babot, 2018). En el área de estudio, estas comunidades desarrollaron la agricultura mi- crotérmica de tubérculos y pseudocereales en una escala doméstica y mantuvieron la caza de fauna silvestre y la colecta vegetal como estrategias de importancia (Olivera, 1998; Babot, 2016). Llevaron adelante un manejo del espacio que combinó el uso de residencias de año redondo, otras estacionales y lugares para el desarrollo de actividades específicas en diferentes zonas ecológicas (Olivera, 1988; López Campeny et al., 2015). El pastoreo y el manejo altitudinal del territorio continúan en la actualidad, como elementos persistentes en los casos de algunas familias locales.

Nuestro objetivo es analizar los conjuntos faunísticos de vertebrados e invertebrados a fin de caracterizarlos desde un punto de vista zooarqueológico y tafonómico. A partir de estos resultados inferir la naturaleza del registro.

Sobre la base de la información proporcionada por el análisis arqueofaunístico y al considerar las asociaciones con otros elementos artefactuales y ecofactuales presentes en los depósitos, así como aspectos estructurales-espaciales de los mismos, interpretamos la existencia de eventos de ofrenda agropastoriles. A la luz de los registros etnográfi-

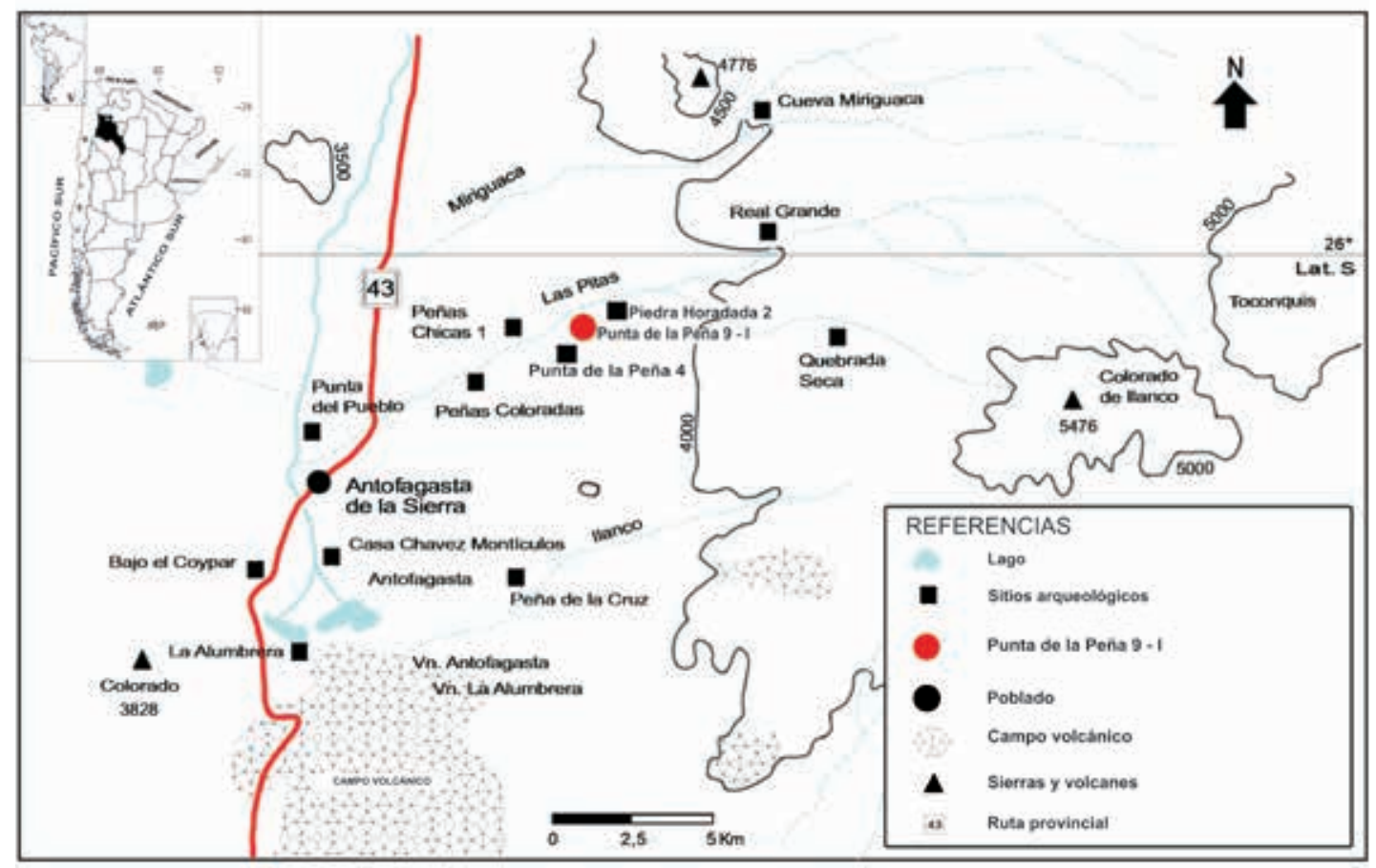

FIGURA 1

Ubicación del sitio Punta de la Peña 9.I, Antofagasta de la Sierra (provincia de Catamarca) en la Puna meridional argentina. 
cos recopilados en la Puna argentino-chilena y el altiplano peruano-boliviano, consideramos a estos conjuntos como el resultado de eventos fundacionales del lugar habitado y de prácticas propiciatorias intrínsecas a la dinámica anual agropastoril de las sociedades del desierto. Éstas se referirían al indisoluble ciclo agrario/pastoril-ritual (Merlino \& Rabey, 1978) o litúrgico-productivo (Kessel \& Llanque Chana, 2004) en donde la protección, la reproducción y la abundancia del ganado se propician mediante el ceremonial religioso. Documentar la existencia de esta clase de prácticas durante el primer milenio de la era, permite fortalecer lo establecido en otros casos de estudio en los Andes Centro-Sur sobre la continuidad milenaria en las tradiciones puneñas.

Antecedentes inmediatos de nuestro estudio están dados por depósitos votivos registrados en Antofagasta de la Sierra en el vecino sitio de Piedra Horadada 2 (Urquiza et al., 2013) (Figura 1), en su estructura 1, en donde neonatos de camélidos de 6 y 12 meses de edad, fibras y cordeles de llama y vicuña, asociados con cuentas, minerales, material lítico, chañar y algarrobo se dispusieron en torno a un monolito o huanca -690-580 años cal. AP-. La estructura 2 del mismo sitio, constituye un refugio natural debajo de un bloque derrumbado cercado por un muro de piedra que contiene un evento funerario inicial de un humano recién nacido con una datación de 1312-997 cal. AP 2ơ para el nivel 3 (Urquiza et al., 2013). También, en el propio sitio Punta de la Peña 9, en su sector III, se depositó un feto humano en una urna sellada con arcilla en el interior de un corral, delimitado por tres rocas - previo a ca. 1290 años AP- (Cohen, 2005). De igual modo, pueden citarse los eventos fundacionales en pozos del sitio Tebenquiche Chico, en el Salar de Antofalla, en la Puna meridional. En el compuesto doméstico TC1 de este asentamiento se realizaron numerosos pozos que en diferentes recintos se situaron mayormente junto a los muros o hacia el centro. Estos se encontraban rellenados principalmente con ceniza y carbón; las inclusiones de fragmentos cerámicos, líticos, cuentas, pigmentos rojos y amarillos y huesos de camélidos enteros y fragmentados, se hallaban dispuestas sin un orden específico, eventualmente con aplicación de pigmento rojo o amarillo y, en algunos casos, respondían a usos sucesivos de un mismo rasgo. Estos pozos han sido interpretados por Haber (2006) como el resultado de la demarcación ritual de la construcción de la vivienda
-1770-1410 años cal. AP-, siendo identificado uno de ellos con la fundación de la casa y los restantes, con sus sucesivas ocupaciones. Del mismo modo, los rellenos de los muros dobles y el espacio entre las piedras internas del mismo contenían elementos enteros y fragmentados (contenedores cerámicos y fragmentos de palas líticas, entre otros) que fueron intencionalmente incluidos a lo largo del uso de la vivienda. Las "mesas" o "festejos" asociados a comidas ritualizadas y las ofrendas de neonatos humanos en fosos estructurados con lajas próximos a los muros y en el centro del Templete de Tulán 54 en el Salar de Atacama, constituyen otras formas de depósitos intencionales de objetos de carácter votivo de la Puna chilena. Los neonatos se encontraban acompañados de placas labradas en oro, cubiletes líticos grabados matados (i.e. intencionalmente perforados) y collar de lapidaria, entre otros elementos -3050-2740 años cal. AP- (Núñez et al., 2017). También en el desierto chileno se han registrado hoyos y "cajas" con ofrendas de mineral de cobre y otros elementos en relación a lugares de tránsito caravanero (Pimentel, 2009, 2013). En el altiplano boliviano se verifican numerosos depósitos votivos; entre ellos pueden citarse los entierros de fetos de llamas en el suelo y en la pared como ofrendas en la construcción de una vivienda de la fase Tiawanaku IV -ca. 1500-1200 años AP- (Silverman, 2004), los pozos con depósitos en una unidad doméstica del componente temprano del sitio Chiripa -ca. 3500 años AP- (Dean \& Kojan, 2001) y los depósitos rituales del sitio San Andrés asociado al complejo Wankarani -ca. 3800-1700 años AP- (Bermann \& Estévez Castillo, 1995).

\section{MARCO CONCEPTUAL Y METODOLÓGICO}

\section{Propiciar en el mundo andino}

En el mundo andino los depósitos de objetos en pozos se vinculan con eventos propiciatorios en los que tiene lugar el acto de challar $\mathrm{u}$ ofrecer elementos a los seres sobrenaturales con el fin de rogar o agradecer, estableciéndose así una reciprocidad. Esta práctica puede tomar también otras formas, como depositar ofrendas en mojones y apachetas (montículos de piedra), o bien en lugares naturales como ojos de agua, cerros y vertientes. Se emplean elementos cúlticos de purificación (agua y coa, 
kopa o koba o pacha en sahumados) y de ofrenda (Merlino \& Rabey, 1983).

Actualmente, en el noroeste argentino, algunos pozos se abren o reabren de acuerdo a un ciclo anual agropastoril de carácter indivisiblemente religioso/ ritual, económico y climático/ecológico, inserto a su vez en un ciclo total (Merlino \& Rabey, 1978), también denominado ciclo ritual anual (Avenburg \& Martínez, 2014) en el marco de celebraciones que recrean experiencias del orden sociohistórico o cosmológico. Éste se organiza en torno a dos momentos centrales y pautados en el año (ceremonial o ritual ordinario sensu Merlino \& Rabey, 1978). Uno de ellos, próximo al carnaval, es cuando tiene lugar la señalada de las nuevas crías de llamas, el casamiento de animales, la chayada y el sahumado de elementos de trabajo y personales. Ocurre entre diciembre y marzo, coincidiendo con la estación húmeda; es un tiempo de fertilidad, de siembra, de primicias, de cosecha. El segundo momento es la celebración de la Pachamama, entre fines de julio y fines de agosto, en la estación seca, cuando la naturaleza llega a un estado límite; constituye un tiempo cargado de sacralidad y recogimiento. Numerosas actividades económicas tienen su inicio en esta época del año, tales como el tejido, el laboreo, la preparación de la tierra, la reparación de las acequias, muros y cercos, corrales y viviendas. Los challacos, acto religioso central de ese momento del ciclo, tienen lugar con variantes en los espacios relacionados con la economía, tales como ojos de agua, manantiales, acequias, lagunas, corrales, rastrojos; con las actividades laborales, como talleres y socavones de minas y con la vivienda, rincón de la habitación, cocina, patios y hornos (Merlino \& Rabey, 1978, 1983; García \& Rolandi, 2000). Se trata de un ciclo temporal y espacial al mismo tiempo, dado que existe una traslación en el espacio que acompaña al desarrollo del tiempo cíclico, como ocurre en los itinerarios vinculados al pastoreo que se encuentran sacralizados (Merlino \& Rabey, 1978).

La señalada es el acto de marcar a los rebaños cortando la punta de la oreja mientras se sahúma, para que cada pastor reconozca a sus animales. Ocurre dentro de un corral cercano a las casas. En la Puna de Jujuy se "enflora" a los camélidos con serpentinas en el cuello y vellones de lana de colores. También se lleva a cabo el casamiento de los animales reuniendo a los machos y hembras de rebaños diferentes, con el compromiso de repartir las futuras crías (Merlino \& Rabey, 1983). De acuerdo a Costa \& Karasik (1996) los actos en torno a la se- ñalada se vinculan con ritos de agradecimiento por los dones recibidos, asociados a la reproducción de la tropa y/o la cosecha.

En Antofagasta de la Sierra, en la Puna de Catamarca, la señalada es un motivo de celebración y se sitúa hacia el final del carnaval e incluso próxima a la Pascua. En esa oportunidad se enflora al ganado anudando flores de lana sin hilar en las orejas y se lo chimpea, colocando largas chimpas de vellón teñido en colores vivos en el pelaje del cuerpo. Toda la ceremonia se acompaña con sahumos de chacha y con ulpada (bebida fría de harina de maíz) que se convida a todos los participantes, incluyendo a la Madre Tierra y al ganado. Se asperja y recitan coplas, siendo el comensalismo parte de la celebración (García \& Rolandi, 2000). En cambio, la corpachada de agosto tiene un carácter más solemne. Se chaya o corpachea en honor a Pachamama, $\mathrm{Pa}$ cha, Pachita o Mamita, convidándola con alimentos, bebidas (ulpada, tulpo, alcohol, bebidas alcohólicas) y coca, ofreciéndole también cigarros que se disponen en el borde del hoyo. El sacrificio de una llama y la ofrenda de su sangre y eventualmente de un feto, también forman parte de este evento. El $1^{\circ}$ de agosto se hila hilo zurdo o lloq'e que se ofrece a Pachamama y se lo lleva atado, como protección. En esa fecha se realiza la limpieza de la casa antes del amanecer, oportunidad en la que se barre y junta la basura que arrastra el viento para quemarla (García \& Rolandi, 2000).

Otras numerosas circunstancias que no son fijas dentro del ciclo anual, pueden apelar a la ofrenda de bienes en pozos, tales como la inauguración de la casa y de otras construcciones, la limpieza de los canales y el traslado del ganado entre puestos ubicados a distintas alturas, por lo que la realización de depósitos votivos constituye una práctica frecuente ligada a distintas ocasiones de agradecimiento o rogativa (Merlino \& Rabey, 1983), incluyéndose estas manifestaciones en el denominado ritual de excepción por tratarse de ceremonias sin una ubicación fija en el tiempo (Merlino \& Rabey, 1978). En particular, las prácticas que acompañan la construcción de la casa invocan a la familia y al pasado mítico, a la vez que construyen y ordenan el cosmos, de acuerdo a los relatos proporcionados por Arnold (1991) para el mundo aymara. De este modo, la casa, imbuida de simbolismo desde los cimientos hasta el techo y también a lo largo de todo su uso, se vuelve un axis mundi en el que se materializan las ideas de género, historia y espacialidad (Arnold, 1991). 
Los pozos abiertos o reabiertos en estas oportunidades simbolizan la boca de Pachamama quien es alimentada mediante las libaciones, "chayas" o "pagos" de alimentos, bebidas, hojas de coca, cigarros y otros diversos elementos, inclusive de la vida cotidiana, dependiendo de la circunstancia de la celebración, los lugares y momentos establecidos para el ritual. Existe desacuerdo entre distintos autores con respecto a la antigüedad del culto a Pachamama o Madre Tierra (Podjacer \& Mennelli, 2009), deidad incorpórea protectora que cobija, posibilita la vida y favorece la fecundidad y la fertilidad (Merlino \& Rabey, 1983), en cuyo nombre se chaya hoy cotidianamente en el noroeste argentino y con quien se dialoga permanentemente. Así, en Antofagasta de la Sierra se manifiesta como diosa tutelar de los ganados y la fertilidad vegetal (cultivos y pastos) y como "dueña" de los animales silvestres y de los metales que se encuentran en las montañas (García \& Rolandi, 2000). Aún cuando no puede establecerse con certeza el referente sagrado en el pasado, la práctica de ofrendar en pozos es de gran antigüedad en el área, tal como ha sido registrada en numerosas ocasiones en los Andes Centro-Sur (Cohen, 2005; Haber, 2006; Urquiza et al., 2013; Núñez et al., 2017; entre otros).

Como sostiene Cladera (2010), en el mundo andino las celebraciones de este tipo están muy pautadas y se verifica el cumplimiento de numerosas reglas que pueden parecer arbitrarias. Estas reglas pueden variar en diferentes localidades y según el propósito de la ofrenda. De igual modo, son de esperar las variaciones a lo largo del tiempo histórico.

\section{Metodología del análisis de los conjuntos}

Es nuestra intención despojarnos de una mirada esencialista sobre las actividades asociadas a los pozos, lo que nos permitirá trabajar con las variantes que se verifican al comparar las prácticas actuales y antiguas. No obstante, apelaremos a comparaciones entre nuestros conjuntos y entre éstos y otros que corresponden a registros actuales cuyos puntos en común nos permitirán sostener el carácter votivo de los contextos que estudiamos.

Diferentes elementos que conforman estas asociaciones permiten sostenerlo, pero en esta ocasión nos referiremos específicamente a los conjuntos óseos de origen animal y a los ítems entomológicos. El análisis de los restos arqueofaunísticos (anatómico, taxonómico y tafonómico) y su valoración contextual posibilitará caracterizar a las estructuras estudiadas y sus contenidos e inferir los momentos del año en que se realizaron los eventos de depositación (estacionalidad). La historia postepositacional de los mismos colaborará en la identificación de los contenidos, en establecer el formato abierto o cerrado de los pozos y evaluar la integridad de los conjuntos. Los elementos recurrentes en los depósitos nos permitirán valorar las pautas seguidas en su realización.

Trabajamos a partir del concepto de depósito intencional de objetos, que implica el acto deliberado de la depositación discreta de elementos con distintos fines, pudiendo abarcar este concepto, entre otros, a los escondrijos de materiales en resguardo de un uso futuro y a las acumulaciones con fines votivos de diversas clases a las que nos hemos referido en párrafos precedentes, inscriptas en la cotidianeidad y los ciclos agropastoriles de los Andes Centro Sur. Otros autores se han referido a estos últimos con la denominación de depósito ritual, un rasgo constituido por un conjunto de objetos apreciados, ceremoniales y productos de sacrificios, los cuales fueron dispuestos intencionalmente con un carácter ritual; el sacrificio y la ofrenda forman el depósito ritual (Dehouve, 2007) [ver también ritual caches en Bermann \& Estévez Castillo (1995)]. Aquí queremos destacar aquello que se ha sostenido sistemáticamente desde la etnografía y arqueología andinas acerca de la indisociabilidad de lo cotidiano y lo votivo en la producción y reproducción doméstica de la sociedad agropastoril (Dean \& Kojan, 2001).

La muestra faunística de los depósitos de objetos de PP9.I, comprende vertebrados e invertebrados. Las identificaciones anatómicas y taxonómicas de los especímenes óseos se basaron en comparaciones con colecciones de referencia modernas que incluyen camélidos silvestres $(V$. vicugna, L. guanicoe) y domésticos (L. glama) del Noroeste argentino con especímenes adultos y subadultos; y atlas osteológicos (Pacheco Torres et al., 1979; Barone, 1987; Benavente et al., 1993; Menegaz, 2000; Loponte, 2004). Se analizaron rasgos y zonas diagnósticas de los especímenes y elementos óseos (Grayson, 1984; Mengoni Goñalons, 1988, 1999; Salemme et al., 1988; Lyman, 1994), y sus medidas se basaron en Driesch (1976), Kent (1982), Izeta (2007) e 
Izeta et al. (2009). Con respecto a la osteometría de individuos adultos, se emplearon las guías osteométricas para huesos largos del esqueleto poscraneal (Kent, 1982) y para huesos cortos (Izeta et al. 2012). No fue posible utilizar las falanges de individuos adultos para distinguir las diferentes especies de camélidos (Lavallée 1990; Izeta 2007) debido a su ausencia en el registro. Se siguió la metodología de Wheeler (1982) para diferenciar distintas especies de Camelidae, y sus clases de edad se estimaron a través de un conjunto de criterios que incluyen atributos óseos (e.g. porosidad, tamaño relativo) y el estado de fusión epifisiaria, erupción y desgaste dental (Kent, 1982; Mengoni Goñalons, 1999; Wheeler, 1999). En relación a los centros de fusión se consideró la nomenclatura y propuesta de Kaufmann (2009). Los parámetros de cuantificación empleados corresponden al número de especímenes (NSP) identificados o no; medidas de abundancia taxonómica: número de especímenes identificados por taxón (NISP), y el número mínimo de individuos (MNI) teniendo en cuenta el criterio de lateralidad y fusión de los especímenes; y medidas de abundancia de partes esqueletarias: número mínimo de elementos (MNE) tomando las zonas diagnósticas (Mengoni Goñalons, 1999).

Por otro lado, se han seguido los criterios de Mengoni Goñalons (1988, 1999), Lyman (1994), Reitz \& Wing (1999), entre otros, para el análisis tafonómico y poder establecer los procesos y agentes que afectaron al conjunto óseo. Se determinaron alteraciones térmicas (Nicholson, 1993), la presencia/ausencia de huellas y fracturas de origen cultural y/o no antrópicas (Binford, 1981; Gifford, 1981; Lyman, 1994; Mondini, 2003; Gutiérrez, 2004), se estimaron los estadios de meteorización (Behrensmeyer, 1978), y los colores de las superficies óseas (Munsell, 2009). Las huellas sobre los huesos y los restos de artrópodos se estudiaron en lupa estereoscópica trinocular. Para éstos últimos se empleó el parámetro de cuantificación número de restos de insectos (NIR). Su taxonomía y etología se basó en Hinton (1946), Piek (1985), Driesche \& Bellows (1996), Flores \& Gómez (2005), Vargas (2006, 2007), Claps et al. (2008), Huchet et al. (2013), Roig-Juñent et al. (2014) y Fernández Gayubo \& Pujade-Villar (2015), además se consultó la colección entomológica de la Fundación Miguel Lillo (Tucumán, Argentina).

Consecuentemente, el estudio de los restos faunísticos de los depósitos de PP9.I, nos permitirá acercarnos al entendimiento de las prácticas propiciatorias de las sociedades agropastoriles puneñas inscriptas en los ciclos anuales en el pasado precolonial, focalizando en el uso de la fauna y su importancia material y simbólica (Duviols, 1976; Arnold, 1998; Göbel, 2000-2002; Berenguer, 2004; Haber, 2006; Nielsen, 2006; Urquiza et al., 2013).

\section{UN CASO DE ESTUDIO EN ANTOFAGASTA DE LA SIERRA, PUNA MERIDIONAL ARGENTINA}

Los conjuntos faunísticos que estudiamos proceden del recinto E3 del sitio Punta de la Peña 9 (PP9) en su sector I (Babot et al., 2007). PP9 constituye un asentamiento agropastoril complejo compuesto por recintos de diferente funcionalidad, incluyendo ámbitos funerarios, reparos rocosos, manifestaciones rupestres, basurales y áreas de molienda, cuya ocupación corresponde a los dos últimos milenios (López Campeny, 2000; Babot et al., 2006). En el recinto E3 se han reconocido cinco momentos de ocupación que se escalonan entre los 1430 \pm 60 AP, 1530-1181 años cal. AP 2o' (LP-2106, carbón) y los $1180 \pm 70$ AP, 1295-926 años cal. AP 2o' (LP 2104) aunque existen indicios de ocupaciones pre-existentes (Babot, 2011). Cada una de ellas puede ser reconocida por sus particularidades, pero en todas priman los elementos que sugieren la realización de múltiples actividades, incluyendo la preparación y almacenamiento de alimentos y diversas tareas artesanales en torno a una o más estructuras de combustión, a modo de un patio. El encierro de ganado Camelidae se ha registrado en varias de las ocupaciones; algunas de esas oportunidades corresponden a usos del lugar como corral (Babot et al., 2006; Babot, 2011).

El recinto E3 destaca por sus dimensiones, de aproximadamente $6 \mathrm{~m}$ de diámetro, y en la terraza estructural ubicada en la margen izquierda del Río Las Pitas. Conforma un conjunto arquitectónico con otros recintos adosados de menores dimensiones y diferente funcionalidad que ocupa una posición central en el sitio. Corresponde a un espacio semitechado, semisubterráneo de cuidada arquitectura, construido con un zócalo de piedras grandes, calzadas por otras menores y aprovechando porciones de afloramientos ignimbríticos que se prolongan en una banqueta interna; las juntas inferiores $y$ el piso presentan un fino trabajo. Las rocas del 
zócalo se disponen con su cara más ancha hacia el interior del recinto y rematan en otras dispuestas horizontalmente, que podrían haber conformado la base de un muro en piedra en algunos sectores. En las zonas de contacto con recintos adosados ocurren muros dobles, mientras que en otros sectores se verifica la presencia de alineaciones simples de piedra poco formales, que siguen aproximadamente la curvatura del paño rocoso interno. Topográficamente, éstas coinciden con el remate del zócalo por lo que se trataría de litos dispuestos semi-superficialmente, a unos $50 \mathrm{~cm}$ de distancia del mismo (Babot, 2011).

En el espacio comprendido por el relleno del muro se encuentran concentraciones discretas de materiales que conforman depósitos intencionales de objetos, espacialmente delimitados por arreglos simples de tres a cuatro piedras (Babot et al., 2007). Estos depósitos se presentan como estructuras de cavado y relleno (pozos) o bien, como acumulaciones discretas de materiales en el interior del muro, próximos a la superficie del zócalo. Inicialmente se identificaron 4 depósitos ubicados en distintos puntos cardinales en relación con la disposición de E3: norte (1 acumulación), sur (1 pozo), sureste (1 pozo que se subdivide en profundidad) y oeste (1 acumulación) (Babot et al., 2007), a los que se suman otras concentraciones acotadas de materiales y elementos artefactuales colocados en el muro, que fueron localizados más recientemente.

Los elementos contenidos varían en cada depósito, pudiendo incluir vegetales carbonizados y sin carbonizar, vegetales modificados, coloreados y manufacturados; minerales en polvo, cristales o agregados nodulares blanquecinos, negros, rojizos, amarillos y verdes; material lítico tallado y modificado por abrasión, fragmentos cerámicos con residuos adheridos o sin ellos; artefactos metálicos; objetos perforados (cuentas y pendientes) terminados, sin terminar, fallidos y fracturados en minerales verdes de cobre, azules y blancos, en rocas metamórficas y en valva; fragmentos de minerales verdes y nódulos de aragonita blanca (roca empleada localmente en la manufactura de cuentas); y material faunístico diverso (Babot et al., 2007; Aguirre, 2012). Estos últimos destacan en todos los depósitos, pudiéndose citar partes óseas, vellón y excrementos de especies de Camelidae, pelo, eventualmente cortado y quemado, plumas y fibras manufacturadas incluyendo cordelería monocroma y bicolor sin teñir y teñida. También se han recuperado partes de invertebrados y lentes de capullos y pupas que serán motivo de evaluación como indicadores de la historia postepositacional de los depósitos.

Uno de los eventos de cavado y/o depositación es contemporáneo a la construcción inicial de E3 (1430 \pm 60 AP, 1530-1181 años cal. AP 20'). Esto se infiere de la disposición de algunos de los elementos depositados, aprisionados entre las rocas y fijados por argamasa y de una datación obtenida para el depósito del Sur (DIO E8), correspondiente a $1465 \pm 29$ AP, 1516-1292 años cal. AP 2o' (AA 89390, endocarpos de chañar) (Babot, 2011), próxima al inicio de la ocupación del lugar. Este depósito es el más importante de todos los registrados por su formalidad, tamaño y contenido. Formalmente corresponde a un pozo de contorno irregular pero claramente definido, con la presencia de una roca alargada, monolito o huanca, colocada de manera vertical en posición central, sobre y en torno a la cual se dispusieron los demás elementos que componen este conjunto. Otros depósitos se ubican en momentos posteriores del uso del recinto E3 por lo que, en su conjunto, dan cuenta de que el interior de los muros habría seguido funcionando como un ámbito para estas prácticas, acompañando el uso de ese espacio. Al menos otros dos depósitos datados corresponden a momentos de ocupación intermedios de E3: el emplazado al Norte (DIO E2), 1269 \pm 29 AP, 1290-1072 años cal. AP 20' (AA 89389, endocarpos de chañar) y el emplazado al Sureste (DIO D8), 1280 \pm 89 AP, 1415-929 años cal . AP 20’ (LP 2344, carbón) (Babot, 2011) (Figura 2).

\section{RESULTADOS}

A continuación se describen sintéticamente los contenidos de los depósitos analizados y los resultados del análisis arqueofaunístico, discriminados por depósito de origen. Un sumario de estos resultados se provee en las Tablas 1 a 7 .

Depósito Norte (DIO E2). 1269 \pm 29 años AP, 1290-1072 años cal. AP 2o' (AA 89389, endocarpos de chañar) (Babot, 2011). Ausencia de estratigrafía. Compuesto por una acumulación discreta y somera de los siguientes elementos. Vegetales: endocarpos y semillas de algarroba (Prosopis sp.), endocarpos de chañar (Geoffroea decorticans) enteros y perforados (cuentas), marlos de maíz (Zea 


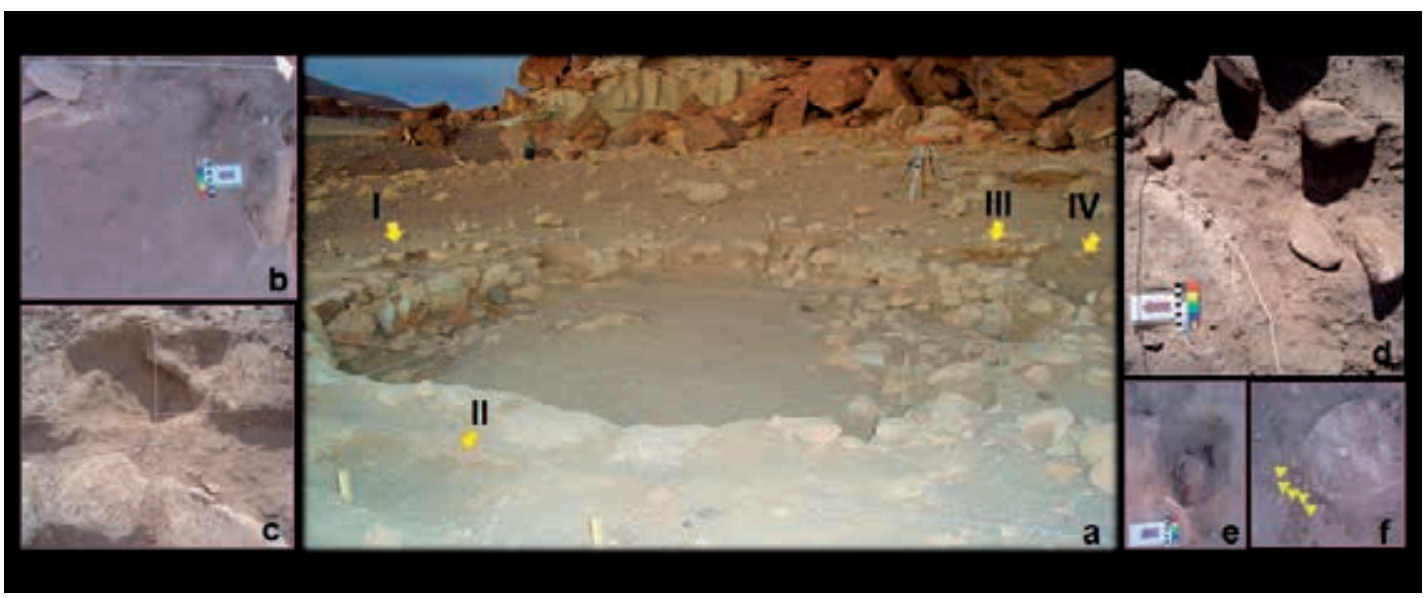

FIGURA 2

a) Localización de los depósitos de objetos en torno a la Estructura 3 (PP9.I). Depósito Norte: I; Depósito Oeste: II; Depósito Sureste: III y Depósito Sur: IV. b) Vista del depósito Norte. c) Vista del depósito Oeste. d) Detalle del muro perimetral (línea blanca), un fragmento de mano de molino con residuos blancos y rocas sueltas contorneando el depósito Sureste. e y f) Depósito Sur. En e) se aprecia el detalle de la mandíbula de camélido cría colocada en torno a la roca central o huanca en el pozo Sur; en f) hilera, de cuentas confeccionadas en minerales verdes de cobre y endocarpos de chañar colocadas intencionalmente en el foso, contorneando el monolito.

mays). Minerales: cristales fibrosos de yeso, 1 artefacto lítico tallado en vulcanita, 1 nódulo de vulcanita y 1 cuenta fallida de mineral verde.

En el depósito Norte, un $55,5 \%$ de la muestra total ósea faunística corresponde a camélidos (Tabla 1), de los cuales se identificaron un Lama glama adulto (más de 36 meses) -dos costillas $\left(8^{\circ}-11^{\circ}\right)$ con dos huellas de corte, vértebra torácica fusionadas y metatarso derecho (con cinco marcas de corte gruesas y finas sobre el extremo proximal)- y un individuo Camelidae cría menor de 9 meses, cuyas partes esqueletales no están fusionadas -escápula derecha (con un punto de percusión en la fosa subescapular), húmero derecho, dos vértebras torácicas, dos costillas, isquion derecho, y tibia derecha)- (Tablas 2 y 3; Figura 5a). El isquion del neonato presenta huellas de seis incisiones finas realizadas con un instrumento fi- loso (Tabla 5 y 6). La epífisis proximal del húmero muestra hinchazones irregulares lo que pudo provocar una desviación de la pata derecha delantera, probablemente producto de raquitismo, similar a la descripta por Baker \& Brothwell (1980: 57) (Figura 3-a).

Se observa la acción de agentes postdepositacionales en algunos elementos óseos: un puncture sobre el húmero, y marcas de pequeños roedores, principalmente sobre el individuo cría: isquion, vértebra torácica, húmero, y sobre una costilla del adulto. Los huesos muestran fracturas frescas y secas en una proporción similar, predominando las escalonadas y transversales (Tabla 7). Las superficies óseas presentan colores que varían entre 10YR7/4 y $2,5 \mathrm{Y} 8 / 2$ relacionados con estadios de meteorización 2 y 3; los más claros (10YR8/1) corresponden a estadios 3 y 4 .

\begin{tabular}{|c|c|c|c|c|c|c|c|c|c|c|c|c|c|c|c|c|c|}
\hline Clase & \multicolumn{11}{|c|}{ Mammalia } & Aves & \multicolumn{5}{|c|}{ Insecta } \\
\hline Taxón & \multicolumn{2}{|c|}{ Rodentia } & \multicolumn{2}{|c|}{ Phyllotis sp. } & \multicolumn{2}{|c|}{ Artiodactyla } & \multicolumn{2}{|c|}{ Camelidae } & \multicolumn{2}{|c|}{$\begin{array}{c}\text { cf. Lama } \\
\text { glama }\end{array}$} & \multirow{2}{*}{$\begin{array}{c}\text { NISP } \\
\text { total }\end{array}$} & \multirow{2}{*}{\begin{tabular}{|c|}
$\begin{array}{c}\text { Passeriformes: } \\
\text { Rhynocryptidae: } \\
\text { T. fuscus }\end{array}$ \\
NP \\
\end{tabular}} & \multirow{2}{*}{$\begin{array}{c}\text { Coleoptera: } \\
\text { Tenebrionidae: } \\
\text { P. mamillonea }\end{array}$} & \multirow{2}{*}{$\begin{array}{c}\text { Hymenoptera: } \\
\text { Chrysididae }\end{array}$} & \multirow{2}{*}{$\begin{array}{c}\text { Lepidoptera } \\
\text { NIR }\end{array}$} & \multirow{2}{*}{$\begin{array}{l}\mathrm{Pi} \\
\text { NIR }\end{array}$} & \multirow[t]{2}{*}{$\begin{array}{l}\text { NIR } \\
\text { total }\end{array}$} \\
\hline Depósito & NISP & $\%$ & NISP & $\%$ & NISP & $\%$ & NISP & $\%$ & NISP & $\%$ & & & & & & & \\
\hline Norte & - & - & - & - & 12 & 44,5 & 12 & 44,5 & 3 & 11 & 27 & - & - & - & - & - & - \\
\hline Oeste & 5 & 12 & 13 & 31 & 10 & 24 & 13 & 31 & 1 & 2 & 42 & - & - & - & 1 & 12 & 13 \\
\hline Sur & - & - & - & - & 30 & 56 & 24 & 44 & - & - & 54 & 1 & 1 & 1 & 1 & 3 & 5 \\
\hline Sureste & - & - & - & - & 22 & 35,5 & 18 & 29 & 22 & 35,5 & 62 & - & 1 & - & - & - & 1 \\
\hline $\begin{array}{l}\text { NISP } \\
\text { total }\end{array}$ & 5 & 7 & 13 & 3 & 74 & 40 & 67 & 36 & 26 & 14 & 185 & 1 & 2 & - & 2 & 15 & 19 \\
\hline
\end{tabular}

TABLA 1

Composición de la muestra faunística de los depósitos de E3 (PP9.I) discriminada en vertebrados e invertebrados. NISP: Número de Especímenes Identificados; NP: Número de plumas; NIR: Número de Restos de Insectos; Pi: Puparios indetermindos. 


\begin{tabular}{|c|c|c|c|c|c|c|c|c|c|}
\hline \multicolumn{2}{|c|}{ Camelidae } & \multicolumn{7}{|c|}{ MNE } & \multirow{3}{*}{ MNI } \\
\hline \multirow[t]{2}{*}{ Elemento } & \multirow[t]{2}{*}{ Depósito } & \multicolumn{3}{|c|}{$\begin{array}{c}\text { Sin } \\
\text { lateralidad }\end{array}$} & \multicolumn{2}{|c|}{$\begin{array}{c}\text { No } \\
\text { fusionado }\end{array}$} & \multicolumn{2}{|c|}{ Fusionado } & \\
\hline & & $\mathrm{NF}$ & F & nd & $\mathrm{i}$ & $\mathrm{d}$ & i & d & \\
\hline \multirow{3}{*}{ Dientes } & $O$ & & & 2 & & & & & 1 \\
\hline & $\mathrm{S}$ & & & 10 & & & & & 1 \\
\hline & SE & & & 12 & & & & & 2 \\
\hline \multirow{3}{*}{ Cráneo } & $O$ & & & 2 & & & & & 1 \\
\hline & $S$ & & & 5 & & & & & 1 \\
\hline & $\mathrm{SE}$ & & & 2 & & & & & 1 \\
\hline \multirow{3}{*}{ Mandíbula } & $\mathrm{O}$ & & & & 1 & 1 & & & 1 \\
\hline & $\mathrm{S}$ & & & & 5 & & & & 1 \\
\hline & SE & & & & & 1 & & & 1 \\
\hline \multicolumn{10}{|l|}{ Hioides } \\
\hline \multicolumn{10}{|l|}{ Atlas } \\
\hline \multicolumn{10}{|l|}{ Axis } \\
\hline \multicolumn{10}{|l|}{$\begin{array}{l}\text { V. Cervicales } \\
\text { 3-7 }\end{array}$} \\
\hline \multirow{2}{*}{$\begin{array}{l}\text { V. Torácicas } \\
1-12\end{array}$} & $\mathrm{~N}$ & 2 & 1 & & & & & & 2 \\
\hline & SE & & 11 & & & & & & 2 \\
\hline \multicolumn{10}{|l|}{ V. Lumbares } \\
\hline \multicolumn{10}{|l|}{ Sacro } \\
\hline \multicolumn{10}{|l|}{ V. caudal } \\
\hline Hemipelvis & $\mathrm{N}$ & & & & & 1 & & & 1 \\
\hline $1^{\circ}$ costilla & $\mathrm{O}$ & & & & & 1 & & & 1 \\
\hline \multirow{4}{*}{ Costillas } & $\mathrm{N}$ & 2 & 2 & & & & & & 2 \\
\hline & $\mathrm{O}$ & & & & & & 2 & & 1 \\
\hline & $\mathrm{S}$ & & & & & & 1 & & 1 \\
\hline & SE & & & & & 1 & & & 1 \\
\hline Esternebra & $\mathrm{O}$ & & & 2 & & & & & 1 \\
\hline$\Gamma_{-}$ & $\mathrm{N}$ & & & & & 1 & & & 1 \\
\hline Escapula & $\mathrm{O}$ & & & & & 1 & & & 1 \\
\hline $\begin{array}{l}\text { Húmero } \\
\text { (px-dt) }\end{array}$ & $\mathrm{N}$ & & & & & $\begin{array}{c}1 \\
(\mathrm{dt})\end{array}$ & & & 1 \\
\hline Radioulna & & & & & & & & & \\
\hline Carpianos & & & & & & & & & \\
\hline Metacarpo & & & & & & & & & \\
\hline Fémur (px-dt) & & & & & & & & & \\
\hline Rótula & & & & & & & & & \\
\hline Tibi (ne d) & $\mathrm{N}$ & & & & & $\begin{array}{c}1 \\
(\mathrm{px})\end{array}$ & & & 1 \\
\hline 11 bia (px-dt) & SE & & & & $\begin{array}{c}1 \\
(\mathrm{px})\end{array}$ & $\begin{array}{c}1 \\
(\mathrm{px})\end{array}$ & & & 2 \\
\hline Astrágalo & $\mathrm{O}$ & & & & & & 1 & & 1 \\
\hline Calcáneo & $\mathrm{s}$ & & & & & & & 1 & \\
\hline Metatarso & $\mathrm{N}$ & & & & & & & $\begin{array}{c}1 \\
(\mathrm{px}) \\
1 \\
(\mathrm{dt})\end{array}$ & 1 \\
\hline & $\mathrm{O}$ & & & 1 & & & & & 1 \\
\hline (px-dt) & $\mathrm{S}$ & $\begin{array}{c}1 \\
(\mathrm{dt})\end{array}$ & & & & & & & 1 \\
\hline Falange 1 & & & & & & & & & \\
\hline & $\mathrm{S}$ & 2 & & & & & & & 1 \\
\hline Falange 2 & SE & $\begin{array}{c}1 \\
(\mathrm{dt})\end{array}$ & & & & & & & 1 \\
\hline Falange 3 & $\mathrm{O}$ & & & 1 & & & & & 1 \\
\hline Falange 3 & $\mathrm{SE}$ & & & 1 & & & & & 1 \\
\hline Total & & 8 & 10 & 40 & 8 & 11 & 2 & 4 & \\
\hline
\end{tabular}

TABLA 2

Perfil de partes esqueletales y piezas dentales de Camelidae de los depósitos intencionales de objetos de E3 (PP9.I). Referencias: NF: no fusionado, F: fusionado, nd: no determinado, i: izquierdo, d: derecho, px: proximal, dt: distal, V.: vértebra.

\begin{tabular}{|c|c|c|c|c|}
\hline Depósito & $\begin{array}{c}\text { Centro de } \\
\text { Fusión/ } \\
\text { Piezas } \\
\text { dentales } \\
\end{array}$ & Estado & $\begin{array}{c}\text { Edad } \\
\text { estimada } \\
\text { (meses) }\end{array}$ & $\begin{array}{c}\text { Clase } \\
\text { de edad } \\
\text { estimada }\end{array}$ \\
\hline Norte & \begin{tabular}{|c} 
ESC1 \\
HU5 \\
VT1 \\
VT2/VT3 \\
COS1 \\
PE1 \\
TI2 \\
MT1 \\
MT2 \\
VT \\
COS1 \\
\end{tabular} & $\begin{array}{l}\text { NF } \\
N F \\
N F \\
N F \\
N F \\
N F \\
N F \\
F \\
F \\
F \\
F \\
\end{array}$ & $\begin{array}{c}-9 \\
-6 \\
-3 \\
-36 / 48 \\
-30 \\
-30 \\
-6 \\
30 / 36+ \\
6+ \\
36 / 48+ \\
36 / 48+ \\
\end{array}$ & Adulto \\
\hline Oeste & $\begin{array}{c}2^{\circ} \text { molar } \\
\text { ESC1 } \\
\text { COS1 } \\
\text { COS1 }\end{array}$ & $\begin{array}{c}\text { Dentro del } \\
\text { alveolo } \\
\text { NF } \\
\text { NF } \\
\text { F } \\
\end{array}$ & $\begin{array}{c}-9 / 12 \\
-9 \\
-30 \\
36-48+ \\
\end{array}$ & Adulto \\
\hline Sur & $\begin{array}{c}3^{\circ} \text { molar } \\
\text { MC1/MT1 } \\
\text { FM } \\
\text { COS1 } \\
\end{array}$ & $\begin{array}{c}\text { Dentro del } \\
\text { alveolo } \\
\text { NF } \\
\text { NF } \\
\text { F } \\
\end{array}$ & $\begin{array}{c}24 / 30+ \\
-30 \\
-30 \\
36-48+ \\
\end{array}$ & $\begin{array}{c}\text { Juvenil/ } \\
\text { subadulto } \\
\text { Adulto }\end{array}$ \\
\hline Sureste & $\begin{array}{c}\text { Premolar } \\
\\
\text { TI1 } \\
\text { COS1 } \\
\text { VT }\end{array}$ & $\begin{array}{c}\text { Infundíbulo } \\
\text { abierto } \\
\text { NF } \\
\text { NF } \\
\text { NF }\end{array}$ & $\begin{array}{l}-6 \\
-30 \\
-30 \\
-30\end{array}$ & $\begin{array}{c}\text { Cría } \\
\text { Juvenil/ } \\
\text { subadulto }\end{array}$ \\
\hline
\end{tabular}

TABLA 3

Estimación de la edad según el estado de las suturas de los huesos y desarrollo dentario de los camélidos de los depósitos intencionales de objetos de E3 (PP9.I). Nomenclatura de centros de fusión de Kaufmann (2009).

Depósito Oeste (DIO H5). Sin datar. Ausencia de estratigrafía. Compuesto por una acumulación discreta de los siguientes elementos. Vegetales: endocarpos de chañar enteros y perforados (cuentas), ocasionalmente termoalterados, endocarpos y semillas de algarroba, marlos de maíz, vegetales leñosos carbonizados y sin carbonizar y 1 cordel vegetal monocromo grueso. Minerales: 4 fragmentos de minerales verdes de cobre; material lítico tallado en sílice rosado.

El conjunto faunístico comprende material óseo, cartilaginoso, vellones y artrópodos. Dentro de los invertebrados se recuperaron un capullo de Lepidoptera (MNI: 1) y fragmentos de puparios eclosionados sin identificar (MNI: 12).

Un 33\% del total de los elementos óseos corresponden a camélidos (MNI: 2) (Tabla 1), de estos, 2 son fragmentos de piezas dentales (molar). Se identificaron un Camelidae $\leq 9$ meses de edad-cráneo/oído izquierdo, palatino izquierdo, mandíbula derecha e izquierda (en la derecha se observa el $2^{\circ}$ molar en el alveolo sin erupcionar), escápula derecha NF, esternebras $\left(2^{\circ}\right.$ y $\left.3^{\circ}\right)$, una $1^{\circ}$ costilla dere- 


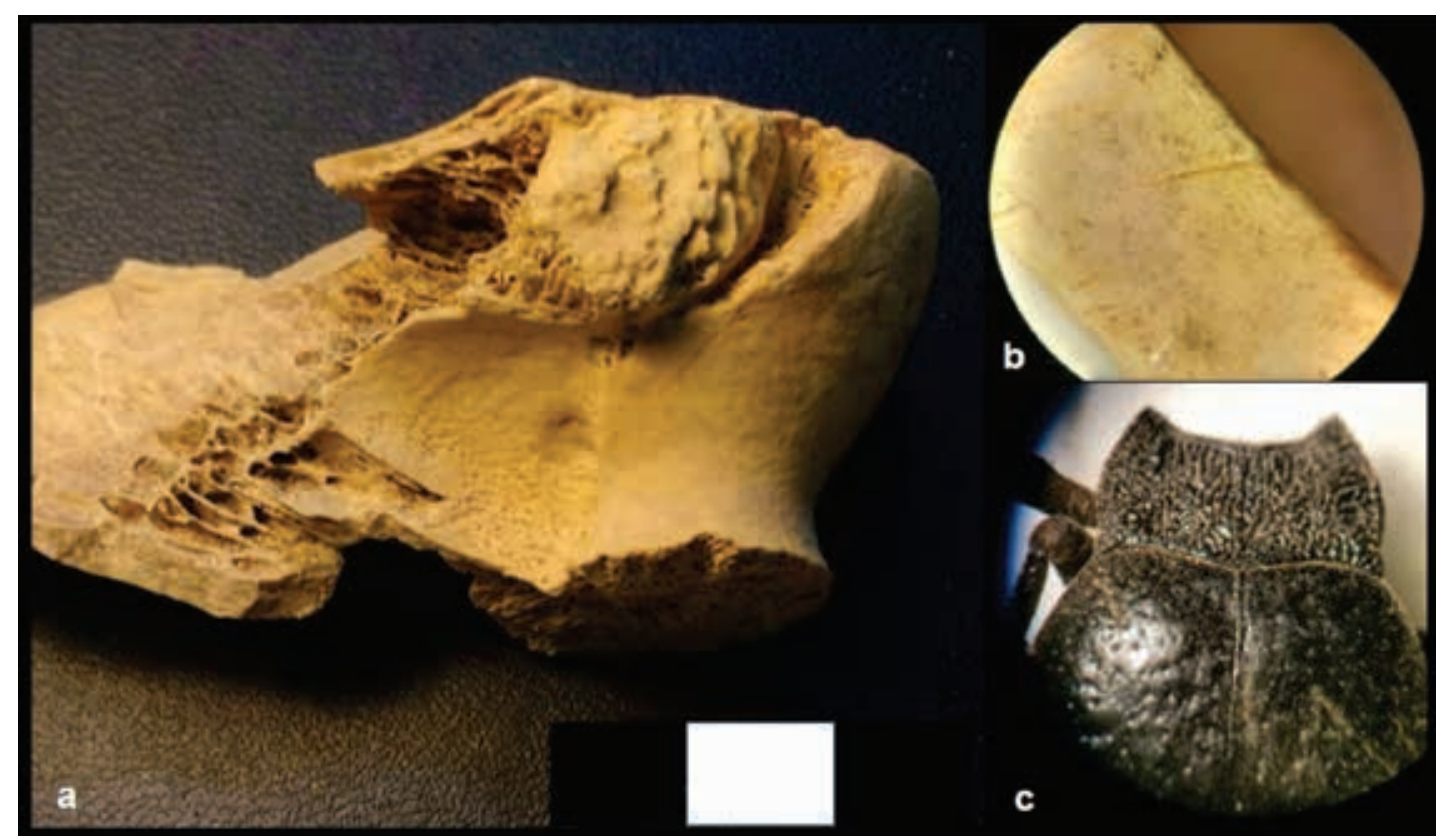

FIGURA 3

Vertebrados e invertebrados de los depósitos de objetos del sitio PP9.I (E3). a) Húmero de camélido neonato mostrando una inflamación irregular sobre la epífisis proximal. b) Marcas de corte sobre la superficie de una costilla de camélido y c) Pronoto de Tenebrionidae.

cha NF con dos incisiones finas intencionales sobre el extremo esternal, metapodio (diáfisis), astrágalo izquierdo y $3^{\circ}$ falange-; y un individuo Camelidae adulto, entre 36 y 48 meses de edad -dos costillas izquierdas-, (Tablas 2, 3 y 4; Figura 5b). Los maxilares presentan marcas de la acción de roedores pequeños y en una rama mandibular se observa un puncture. Una costilla contiene surcos (furrows) y tres cortes finos intencionales; un corte de este tipo también se registra en el fragmento de hueso plano (Tabla 5 y 6; Figura 3-b).

Los huesos muestran fracturas frescas y secas en una proporción similar, predominando las escalonadas y longitudinales, con estadios de meteorización de 2 a 4 (Tabla 7). En algunos sectores del depósito las superficies óseas presentan precipitación de $\mathrm{CO}_{3}$ y en los próximos al muro algunos fragmentos han estado expuestos a la intemperie (sólo del lado opuesto al que apoya en el suelo). Las superficies de las partes esqueletales vinculadas con una cueva de roedores que afecta a la parte superior del depósito presentan en general colores 2,5 YR 8/2; para el resto de los huesos el color es más oscuro (10 YR $8,4)$. El $43 \%$ de la muestra corresponde a Rodentia (NISP: 18). Dentro de ésta, el $31 \%$ corresponde al cráneo, hemimandíbulas y vértebras de un individuo cf. Phyllotis sp., cuyo color es 2,5 YR 7/4.
Depósito Sur (DIO E8). 1465 29 años AP, 1516-1292 años cal. AP 20' (AA 89390, endocarpos de chañar) (Babot, 2011). Ausencia de estratigrafía. Compuesto por una acumulación de los siguientes elementos en un pozo. Vegetales: endocarpos y semillas de algarroba, endocarpos de chañar enteros y perforados (cuentas), marlos de maíz, vegetales leñosos carbonizados (incluyendo la presencia de plantas sahumadoras Parastrephia sp. y Senecio santelices, sensu Aguirre, 2012) y sin carbonizar, vegetales leñosos modificados por corte y desbaste coloreados en tonos rojo-violáceos y sin colorear correspondientes a sectores basales del tallo y vegetales leñosos manufacturados en la forma de palitos desbastados y aguzados. Minerales: agregados nodulares blanquecinos compuestos de fosfatos (alumbres?), cuarzo y moscovita; agregados nodulares marrón-rojizos de arcillas esmectíticas; minerales rojizos, negros y blancos en polvo; material lítico tallado en vulcanita y cuarcita; 1 fragmento de pala en vulcanita; 1 pequeño artefacto modificado por uso como mano de moler y percutor; 1 base de molienda en cuarcita sobre la que se molió una sustancia mineral rojiza; 7 cuentas de aragonita verde y blanca, una de ellas con restos de un fino cordel que se hallaron contorneando el monolito junto a otras cuentas de chañar y 1 pequeño 
fragmento cerámico. Otros elementos biológicos: pelo humano cortado, vellones, 1 elemento conformado por un vellón al que se adhieren dos finos cordeles monocromos, similar a las actuales chimpas para el floreo del ganado, una pluma cobertora de un ave pequeña que se alimenta de artrópodos (Passeriformes: Rhinocryptidae: Teledromas fuscus). En asociación con las partes esqueletales animales se recuperaron elementos de invertebrados, 2 cuentas terminadas en valva, un individuo adulto Coleoptera: Tenebrionidae: Psectrascelis mamillonea (Lacordaire, 1830) (MNI: 1) (Figura 3-c), un capullo de Lepidoptera (MNI: 1), un puparium eclosionado de Hymenoptera: Chrysididae (MNI: 1) y 3 pupas eclosionadas sin identificar (MNI: 3 ).

De un NISP total de 54 del conjunto esqueletal animal, 10 corresponden a piezas dentales de Camelidae (fragmentos de incisivos y molares) en asociación con partes de una mandíbula cuyo $3^{\circ}$ molar se observa dentro del alveolo sin erupcionar (Tabla 1). Se identificaron Camelidae (MNI: 2), incluyendo un juvenil o subadulto (entre $24 \mathrm{y}$ 30 meses de edad) -cráneo/oído izquierdo, maxilar izquierdo, metapodio distal NF, calcáneo derecho distal y dos segundas falanges- y un individuo adulto -extremo vertebral costilla $7^{\mathrm{a}}-10^{\mathrm{a}}$ izquierda- (Tablas 2, 3 y 4; Figura 5c). Domina el color 10YR 7/4 en las superficies óseas y 10YR 9,5/2 en las piezas dentales. Los restos óseos presentan escasas marcas de roído, un puncture, y ausencia de huellas antrópicas (Tabla 5 y 6). En algunos casos las fracturas no permitieron distinguir lateralidad (falanges), en toda la muestra predominan las fracturas secas sobre las frescas, correspondiendo en su mayoría a la clase escalonada con un estadio de meteorización 3 (Tabla 7 y Figura 4).

Depósito Sureste (DIO D8). 1280 889 AP, 1415929 años cal. AP 2o' (LP 2344, carbón) (Babot, 2011). Compuesto por la acumulación de los siguientes elementos en dos pozos contiguos (A y B) cuyas bocas se unen conformando una única oquedad más superficialmente. Esta característica indica por defecto una diacronía en la historia del pozo aunque la estratigrafía está ausente. Vegetales: endocarpos y semillas de algarroba, endocarpos de chañar enteros y perforados (cuentas), marlos de maíz, vegetales leñosos carbonizados (incluyendo la presencia de plantas sahumadoras Parastrephia sp. y Senecio santelices, sensu Aguirre, 2012) y sin carbonizar coloreados en tonos rojo-violáceos y sin colorear; vegetales leñosos modificados por corte y desbaste y vegetales leñosos manufacturados en la forma de palitos desbastados y aguzados coloreados en tonos rojo-violáceos y sin colorear. Minera-

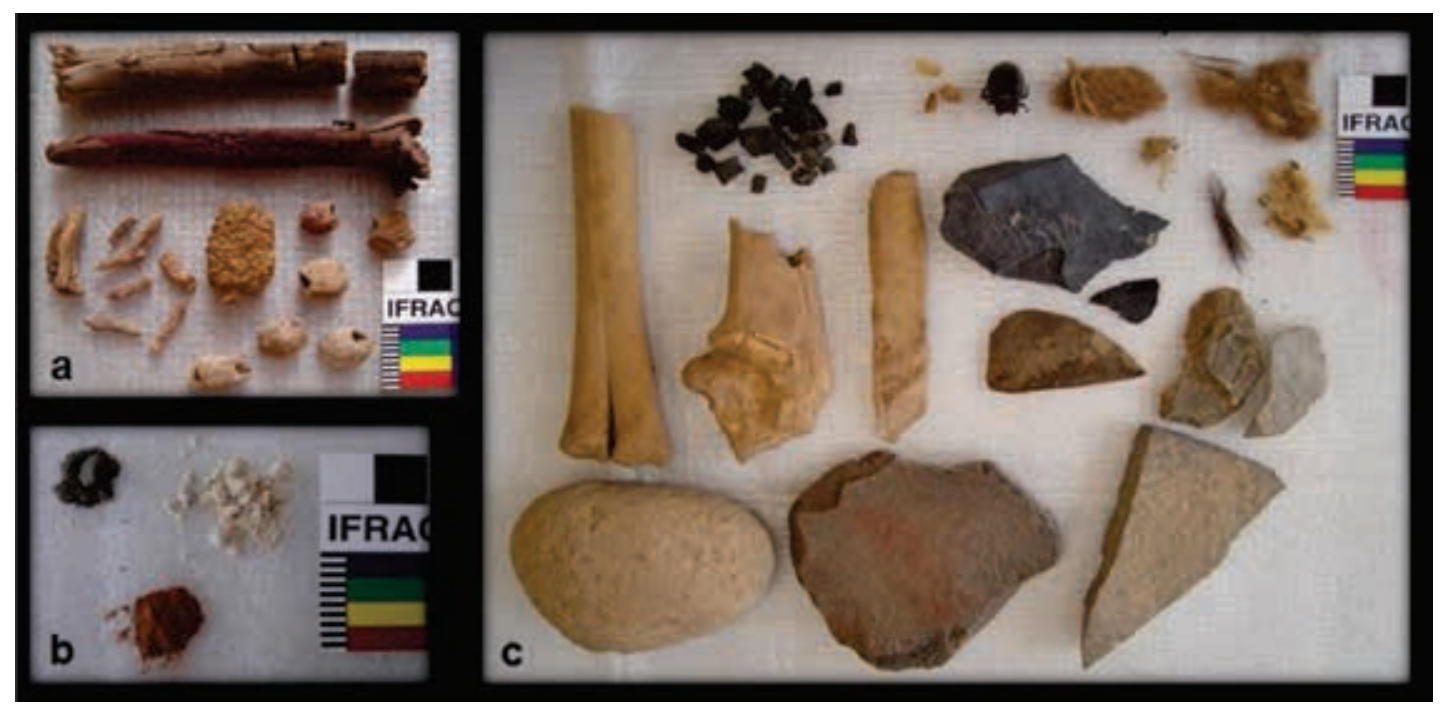

FIGURA 4

Materiales recuperados del depósito Sur. a) Vegetales leñosos manufacturados o con evidencias de corte (coloreados y sin colorear), marlo de maíz, endocarpos de chañar enteros y perforados (cuentas), coloreados y sin colorear. b) Minerales en polvo. c) Artrópodos (pupas y vista dorsal de Tenebrionidae adulto); partes esqueletales, vellones y "flor" de vellón o chimpa que presenta dos finos cordeles de Camelidae; pluma de Passeriforme (Rhynocryptidae); fragmento cerámico; artefactos líticos en vulcanita y cuarcita; mano de molino y percutor; fragmento de pala lítica en vulcanita y molino en cuarcita con residuos de pigmento rojo. 
les: 1 agregado nodular blanquecino de pirrotina y material amorfo, 1 plancha de mica, material lítico tallado en vulcanita, 1 fragmento de un artefacto activo modificado por abrasión y pulido con residuos de una sustancia mineral blanca, 1 fragmento de cuenco cerámico de importante tamaño con daños por termoalteración que presenta sustancias adheridas en su interior y otros 2 fragmentos pequeños. Otros elementos biológicos: pelo humano cortado y pelo humano cortado y quemado, 1 fino cordel monocromo, 1 cordel bicolor grueso anudado (mishmido), vellón, y excrementos de Camelidae compactados que sellaban la parte superior del depósito. Dentro de los invertebrados, 1 cuenta terminada en valva y el exoesqueleto de un coleóptero adulto: Tenebrionidae: Psectrascelis mamillonea (Lacordaire, 1830) (MNI: 1).

Con respecto al material óseo faunístico, de un 64,5\% de la muestra total de Camelidae (NISP: 50 fragmentos óseos y 12 piezas dentales) (Tabla 1), se identificaron 2 individuos, comprendiendo un cf. Lama glama de $\leq 30$ meses -tibia izquierda y derecha, $2^{\circ}$ falange extremo distal y $3^{\circ}$ falange, $3^{\circ}$ costilla derecha, dos vértebras torácicas (11 fragmentos)-, y una cría de Camelidae de $\leq 6$ meses de edad -mandíbula derecha, premolar deciduo con infundíbulo abierto, ocho fragmentos de incisivos $\mathrm{y}$ tres fragmentos indeterminados de piezas dentales, orbital derecho e izquierdo- (Tablas 2, 3 y 4; Figura 5d).

Las partes esqueletales presentan en general color 10YR 6/4 con estadios de meteorización 3, y las piezas dentales 10 YR $8 / 3$. Se registraron marcas de corte realizadas sobre el hueso fresco en la costilla y un incisivo presenta alteración térmica. Una vértebra cervical es el único elemento con marcas de roedor (Tabla 5 y 6). Los huesos se encuentran resecos y fragmentados, observándose fracturas longitudinales y escalonadas principalmente, predominando las secas sobre las frescas. Predominan los estadios de meteorización 3 y 4 y se observa precipitación de $\mathrm{CO}_{3}$ sobre la cara interna de algunos huesos (orbital izquierdo, mandíbula derecha y tibia izquierda). El grado de fragmentación en este caso es mayor a los otros, encontrándose una alta cantidad de fragmentos pequeños, menores a $3 \mathrm{~cm}$ con grado de meteorización 4 (Tabla 7).

\section{ANÁLISIS E INTERPRETACIÓN DE LOS DATOS}

Distribución de la fauna en los depósitos intencionales de objetos

En lo que respecta a las tendencias de la muestra total (NSP: 185), la mayor parte de los restos identificados corresponde a Artiodactyla (40\%), Camelidae $(36 \%)$ y cf. Lama glama (14\%) que componen la fauna de vertebrados de todos los depósitos. En menor medida se identificaron elementos de Rodentia (7\%) y Phyllotis sp. (3\%), asociados a la alteración postdepositacional del depósito oeste (Tabla 1).

En tres de los depósitos (Norte, Oeste y Sureste) hay partes correspondientes a un individuo cría Camelidae; en dos de ellos (Norte y Oeste) se encuentran además partes de un adulto y en el tercero (Sureste), de un subadulto cf. Lama glama (MNI: 2). En todos estos casos las crías de camélidos están representadas por sus lados derechos (sólo una hemimandíbula y elementos de la pata izquierda en el depósito Oeste) y los elementos de los adultos/subadultos son minoritarios con respecto a los de las crías. Por otro lado, en el depósito Sur se verifica una diferencia dada por la ausencia de crías, y la presencia de dos Camelidae, uno subadulto y otro adulto (MNI: 2), cuyas partes se encuentran asignadas a ambas lateralidades. De este modo, el número de ejemplares de camélidos, su edad y

\begin{tabular}{|l|l|l|l|}
\hline Depósito & \multicolumn{1}{|c|}{ NMI } & \multicolumn{1}{|c|}{ Rango etario } & Lateralidad \\
\hline Norte & $\begin{array}{l}\text { 1 Camelidae } \\
1 \text { L. glama }\end{array}$ & $\begin{array}{l}\text { Cría } \leq 9 \text { meses } \\
\text { Adulto }\end{array}$ & $\begin{array}{l}\text { Cría } \leq 9 \text { meses } \\
\text { Adulto } \\
\text { derecha }\end{array}$ \\
\hline Oeste & 2 Camelidae & $\begin{array}{l}\text { Juvenil/subadulto } \leq 30 \text { meses } \\
\text { Adulto } \\
\text { izquierda }\end{array}$ & $\begin{array}{l}\text { izquierda y derecha } \\
\text { izquierda }\end{array}$ \\
\hline Sur & 2 Camelidae & $\begin{array}{l}\text { Cría } \leq 6 \text { meses } \\
\text { Juvenil/subadulto } \leq 30 \text { meses }\end{array}$ & $\begin{array}{l}\text { derecha } \\
\text { derecha e izquierda }\end{array}$ \\
\hline Sureste & $\begin{array}{l}\text { 1 Camelidae } \\
\text { 1 cf. L. glama }\end{array}$ & &
\end{tabular}

TABLA 4

MNI, rango etario y lateralidad de Camelidae de los depósitos intencionales de objetos de E3 (PP9.I). 

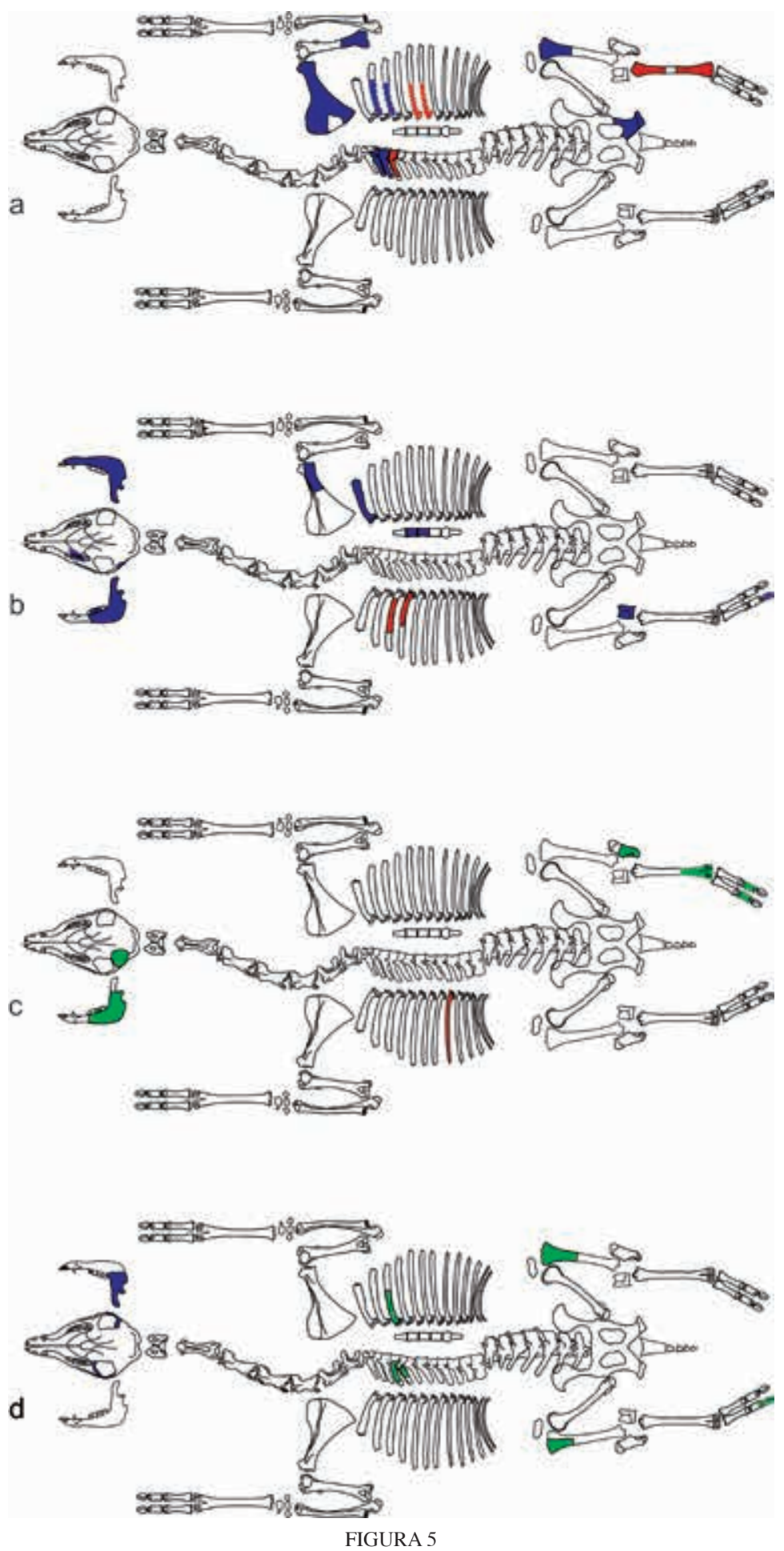

Representación de los distintos elementos anatómicos de camélidos por rango etario y depósito en E3 (PP9.I). a) Depósito Norte, b) Depósito Oeste, c) Pozo Sur y d) Pozo Sureste. Color azul: individuo cría; color verde: individuo juvenil/subadulto y color rojo: individuo adulto. Líneas de puntos: elementos sin lateralidad. 
lateralidad (esta última diferenciada con respecto a la edad) constituyen tres criterios destacados, ya que se verifica la disposición predominante de partes derechas de individuos sin fusionar, mientras que la lateralidad izquierda se restringe a subadultos y adultos, con la presencia recurrente de elementos de dos ejemplares por depósito.

Considerando el perfil de partes esqueletarias de Camelidae, predominan los elementos asignables al cráneo-mandíbula-dientes, situación que se debe a la alta fragmentación de éstos elementos (Tabla 2). En particular para el depósito Norte, no se presentan elementos del cráneo. De los elementos que han podido distinguirse por el grado de fusión, aquellos sin fusionar tienen una representación más amplia (NISP=27) correspondiendo al cráneo, tórax y miembros derechos delanteros y traseros. Los elementos fusionados son menos diversos (NISP=16) e incluyen al tórax y miembros traseros. Las costillas constituyen los únicos elementos en común entre los ejemplares fusionados y sin fusionar; al igual que las patas, están presentes en todos los depósitos. No se registraron elementos anatómicos óseos semifusionados. Considerando las etapas de fusión temprana (Mengoni Goñalons, 1999; Kaufmann, 2009) de algunos elementos óseos (e.g. húmero) y que los nacimientos de camélidos se dan entre noviembre y enero, tendremos que la muerte de las crías ocurrió a fines de invierno. La preservación de los elementos óseos de los individuos inmaduros pudo ser deficiente debido a diferentes propiedades como fusión, densidad mineral, estructura ósea, estado nutricional, estación de muerte, y/o su comportamiento tafonómico contrario al de los individuos maduros (Lyman, 1984, 1994; Symmons, 2002; Álvarez et al., 2010; entre otros). De este modo, la selección de partes según el grado de fusión (edad de los ejemplares sacrificados), constituye otro criterio observado en la conformación de los depósitos. Los ejemplares subadultos y adultos están representados sólo por ciertas partes elegidas. Éstas incluyen elementos de las patas traseras y otros palatables, presentando las costillas y metatarso frecuentes marcas de corte (Norte, Oeste y Sureste) asociados al descarne y la preparación para el consumo. Las marcas de corte en un isquion de cría se deberían en cambio, a la separación lateral del neonato.

Predominan las marcas de origen no antrópico $(\mathrm{N}=50)$ por sobre las antrópicas $(\mathrm{N}=24)$. Éstas incluyen alteración térmica sólo en un fragmento de incisivo, huellas de corte realizadas con un instru- mento de filo fino y otro grueso $(\mathrm{N}=22)$ en los individuos crías (isquion y $1^{\circ}$ costilla) y adultos (costillas y metatarso px); y puntos de impacto $(\mathrm{N}=1)$ en una escápula NF, que se asocian a la preparación de las partes animales con anterioridad a su depositación (Tabla 4 y 5). Los elementos presentes en el depósito Norte evidenciarían un procesamiento de los camélidos más intenso que en los otros depósitos. En el depósito Sur no se registraron huellas antrópicas.

\begin{tabular}{|c|c|c|c|c|c|}
\hline \multirow{2}{*}{ Depósitos/Huellas } & \multicolumn{2}{|c|}{ No Antrópicas } & \multicolumn{4}{|c|}{ Antrópicas } \\
\cline { 2 - 7 } & $\mathbf{R}$ & $\mathbf{C}$ & $\mathbf{A T}$ & $\mathbf{H c}$ & $\mathbf{P i}$ \\
\hline Norte & 29 & $1 \mathrm{p}$ & - & 13 & 1 \\
\hline Oeste & 10 & $1 \mathrm{f}-1 \mathrm{p}$ & - & 6 & - \\
\hline Sur & 6 & $1 \mathrm{p}$ & - & - & - \\
\hline Sureste & 1 & - & 1 & 3 & - \\
\hline NISP total & $\mathbf{4 6}$ & $\mathbf{4}$ & $\mathbf{1}$ & $\mathbf{2 2}$ & $\mathbf{1}$ \\
\hline
\end{tabular}

TABLA 5

Número de huellas de origen antrópico y no antrópico registradas en los elementos óseos de Camelidae de los depósitos intencionales de objetos de E3 (PP9.I).

No Antrópicas: R: roedor, C: carnívoro -p: puncture, f. furrows-; Antrópicas: AT: alteración térmica; Hc: huella de corte; Pi: punto de impacto.

Las marcas no antrópicas se vinculan con el carroñeo postdepositacional de estos contextos dada su situación somera, pudiendo estar sobrerepresentadas en relación a las otras, al ser contadas las marcas de la acción de cada diente. La mayoría corresponde a roedores pequeños $(\mathrm{N}=46)$ afectando a los conjuntos esqueletales de las crías (mandíbulas, vértebra torácica, isquion, costilla, húmero) y juvenil/subadulto (metapodio y falange $\left.2^{\circ}\right)$. Otras marcas incluyen punctures $(\mathrm{N}=3)$ en individuos cría (mandíbula, húmero) y juvenil/ subadulto (metapodio), y furrows en una costilla izquierda de adulto. El accionar de los carnívoros podría vincularse con la extracción de grasa ósea (húmero y metapodio). También se verifica intemperismo sobre todo en el depósito Sur debido a la exposición reciente de parte de los elementos óseos de los depósitos, principalmente por derrumbes de la argamasa del muro perimetral y el colapso de los rellenos arqueológicos durante y $a$ posteriori del proceso de excavación del interior del recinto E3 que dejó expuesta una parte de los materiales óseos del pozo hasta que se concretó su excavación sistemática. Además, el tránsito o pisoteo previo y contemporáneos a la excavación de los depósitos, que se encuentran a poca profundidad desde la superficie actual del terreno, cola- 
boraron en la voladura o corrimiento de los sedimentos superiores en algunos casos, provocando la exposición parcial de los materiales contenidos. En ambos casos, se trata de procesos recientes verificados y documentados durante el trabajo de campo; de ellos, el pisoteo impremeditado sin implicar la exposición de los materiales arqueológicos ha sido sostenido a lo largo de los últimos veinte años por coincidir con una zona de circulación dentro del sitio. Los colores más claros, los estadios más altos de meteorización y de fractura indicarían un cierto grado de remoción asociada a estos procesos.

Se aprecia un alto grado de fragmentación en huesos y dientes, predominando los fragmentos menores a $5 \mathrm{~cm}(\mathrm{~N}=126)$ y siendo minoritarios los elementos enteros $(\mathrm{N}=2)$ (Tabla 6). En particular el depósito Sureste presenta numerosos restos menores a $3 \mathrm{~cm}$. En los depósitos Norte y Oeste los huesos muestran estadios de meteorización más altos y fracturas del lado opuesto al de apoyo en el suelo. En algunos casos la superficie ósea de apoyo en el suelo presenta incrustaciones de granos de arena, por lo que debió haber humedad para que éstos se adhiriesen, dando cuenta al mismo tiempo de un peso sobre los huesos presionados contra el sedimento, compatible con el pisoteo anteriormente referido.

\begin{tabular}{|l|c|c|c|c|c|}
\hline \multicolumn{1}{|c|}{$\begin{array}{c}\text { Camelidae/ } \\
\text { Depósito }\end{array}$} & \multicolumn{2}{c|}{ Norte } & Oeste & \multicolumn{2}{c|}{ Sureste } \\
\hline Elemento & Hc & Pi & Hc & Hc & AT \\
\hline Dientes & & & & & 1 \\
\hline Isquion & 6 & & & & \\
\hline $\mathbf{1}^{\text {a costilla }}$ & 2 & & 2 & & \\
\hline Costillas & & 1 & & 3 & \\
\hline Escápula & 5 & & & & \\
\hline Metatarso px & & & 1 & & \\
\hline Hueso plano & & & & & \\
\hline
\end{tabular}

TABLA 6

Huellas antrópicas en las partes esqueletales de los depósitos intencionales de objetos de E3 (PP9.I). AT: alteración térmica; Hc: huella de corte; Pi: punto de impacto.

La entomofauna indica una serie de procesos posteriores a la realización de los depósitos que podrían haber operado a lo largo de los años durante las estaciones cálidas, de acuerdo a la presencia de pupas de artrópodos y de coleópteros. La ocurrencia de capullos de Lepidoptera en los depósitos Oeste y Sur, podría vincularse con el hábito dermatófago en la etapa larval de las polillas
(Huchet et al., 2013). Estas lepidópteras se habrían visto atraídas a los depósitos por los cabellos humanos, plumas y/o por los vellones, cordeles de fibra animal y restos epidérmicos de los camélidos. El capullo de Chrysididae del depósito Sur se asocia a Lepidoptera, ya que las avispas de esa familia pueden parasitar las pupas de éstas polillas (Driesche \& Bellows, 1996; Fernández Gayubo \& Pujade-Villar, 2015). Algunas avispas incluso paralizan larvas de tenebriónidos para alimentar a sus crías (Piek, 1985). En cuanto a los tenebriónidos, éstos se caracterizan por sus hábitos nocturnos y por enterrarse en la arena o permanecer bajo rocas, hojarasca, estiércol o troncos (Flores \& Gómez, 2005); son principalmente detritívoros por lo que pudieron alimentarse de las ofrendas orgánicas (vegetales y camélidos) en descomposición dispuestos en el interior de los depósitos Sur y Sureste, y en este último, refugiarse bajo la capa de coprolitos que sellaba el pozo.

\begin{tabular}{|c|c|c|c|c|c|c|}
\hline \multirow{2}{*}{ Depósito } & \multicolumn{4}{|c|}{ Fragmentos $(\mathrm{cm})$ óseos y dentales } & \multirow{2}{*}{$\begin{array}{l}\text { Especímenes } \\
\text { completos }\end{array}$} & \multirow{2}{*}{ NSP } \\
\hline & $<1$ & 1 a 2 & 2 a 5 & $>5$ & & \\
\hline Norte & 11 & 5 & 4 & 7 & - & 27 \\
\hline Oeste & 16 & 12 & 5 & 8 & 1 & 42 \\
\hline Sur & 7 & 29 & 16 & 2 & - & 54 \\
\hline Sureste & 14 & 8 & 36 & 3 & 1 & 62 \\
\hline NSP & 48 & 54 & 61 & 20 & 2 & 185 \\
\hline
\end{tabular}

TABLA 7

Grado de fragmentación de la muestra de camélidos de los depósitos intencionales de objetos de E3 (PP9.I).

\section{Cruzando contextos arqueológicos y relatos etnográficos}

A partir de los resultados obtenidos, identificamos una serie de elementos que remiten al carácter pautado de los contextos estudiados. A excepción de los restos de Rodentia y de la pluma de Passeriformes, la mayor parte de la fauna de vertebrados identificada en los pozos y depósitos corresponde a Artiodactyla y camélidos, así como los demás elementos no óseos, tales como los vellones, cordeles y la pieza afín a una flor o chimpa de vellón, haciendo énfasis en el eje de la organización socieconómica agropastoril puneña. Los dos primeros taxa, se relacionarían con la actividad posdepositacional sobre los depósitos de objetos, según la consistencia de su presencia con otros indicadores como madrigueras, huellas de roído sobre los huesos y diversas materias que podrían 
atraer la atención de las aves para su consumo. No obstante, es preciso comentar que se trata de fauna que ha sido registrada en depósitos rituales del sitio Tulán-54 en el Salar de Atacama (Núñez et al., 2017), siendo al menos los roedores pequeños del género Phyllotis interpretados como ofrendas en tales situaciones.

En particular, la edad de los individuos de tres de los depósitos (Norte, Oeste y Sureste) permite hacer referencia a la ofrenda de neonatos de camélidos. Merlino \& Rabey (1983) se refieren al sacrificio de sullos o fetos de llama en los challa$\cos$ de agosto en la Puna de Jujuy: "(...) la ofrenda por excelencia, consistió en depositar en el hoyo de la Pachamama el sullo atalajado, al que se le cubrió con el resto de las ofrendas que quedaban en la mesa devolviéndosele así a la Pachamama, simbólicamente, parte del ganado cuya protección se invocaba“. Por su parte, en la señalada el $s u$ llo es reemplazado por la ofrenda de los cortes de orejas y “(...) las invocaciones y rogativas están particularmente dirigidas a lograr la protección y el "multiplico" del rebaño, lo cual explica el celo por la presencia de todos los animales en el acto. El marco donde se celebra es el corral y el rigor y entrega ritual son similares a los del challaco, aunque aquí apunta un carácter festivo, propio de la abundancia de pastos y animales."

Cladera (2010) relata diversas circunstancias de celebración en las que las reglas establecidas se refieren a la lateralidad; especialmente aluden el lado derecho. Una de esas circunstancias es la captura de los animales durante la "pialada" en las señaladas: "Una vez enlazado correctamente, el animal debe ser apuntado hacia el sol naciente y recién ahí se le enlaza las patas para voltearlo, lo que asimismo debe hacer con el flanco derecho hacia arriba", según relata Cladera (2010: 121) para Isla de Cañas. También durante las señaladas, hacia el final de la ceremonia, tiene lugar el "Casamiento", cuya finalidad es propiciatoria y tiene el objetivo de favorecer la multiplicación de los animales al año siguiente. Según el relato de Cladera: “(...) se agarra un ternerito macho y una hembra de menos de un año, se los une en posición de cópula (siempre con el flanco derecho hacia arriba), y se los ata" (Cladera, 2010: 122). Por su parte, en Cochinocas “(...) se agarra un casal de llamitas del año (Teques), y se las pone una al lado de la otra, el macho a la derecha" y al padrino, también un animal nuevo de la tropa, se lo hace sentar a la derecha del casal, mientras que la madrina ocupa el lado izquierdo (Cladera, 2010: 122).

La incompletitud de las ofrendas de camélidos en los depósitos estudiados encuentra similitud en lo sostenido por Cladera (2010) sobre la partición de las miniaturas de camélidos durante la Señalada. El autor relata observaciones realizadas en Cochinoca: “(...) el anfitrión tenía preparados animalitos en miniatura moldeados en llicta (una masilla de cenizas de plantas, muy alcalinas, empleadas para saborizar la coca). Tenía una llamita y un torito, coincidiendo con la hacienda afectada. Comenzaba "sacrificando" el muñequito mediante una incisión en forma de cuña en el cogote; el pedacito extraído (denominado "sangre") se ofrecía a la Tierra, mientras que el resto del muñequito era despiezado y repartido entre todos los asistentes" (Cladera, 2010: 121). Esta situación podría corresponder a un simulacro de comensalismo pero termina resultando en ello pues se verifica en el acto de coquear con la porción de llicta que se recibe, que implica el compartir sin ingerir.

En los depósitos de E3 se recuperaron elementos de un número reducido de camélidos, dos en cada caso. En tres de ellos (Norte, Oeste y Sureste) corresponden a individuos de edades diferenciadas, por un lado, crías ( $\leq 6$ meses y $\leq 9$ meses de edad), y por otro lado, juveniles/subadultos y adultos, con una menor representación de camélidos fusionados. Según las partes representadas, los subadultos y adultos identificados podrían corresponder a instancias de comensalismo mediante el sacrificio y el convite de alimento cocido, pues se trata de costillares y patas con presencia de huellas de corte. Esta pauta, en particular la representación de las patas y de la cabeza de un individuo subadulto en el pozo Sur, encuentra similitudes en la elaboración de la tistincha, comida característica de las corpachadas de la Puna de Jujuy, alimento predilecto de Pachamama, elaborado mediante la cocción de ingredientes secos: carne seca de cabezas y patas o chalona de animales grandes, maíz y habas (Pazzarelli, 2014; Bugallo, 2015).

Los elementos correspondientes a los neonatos, en cambio, procederían del sacrificio u ofrenda de partes de una mitad de las crías. Resulta representativa sobre la diferencia de edades la siguiente referencia de Merlino \& Rabey (1983): “(..) si bien las normas que limitan la matanza de animales jóvenes y de hembras fecundas son de carácter profano, fundadas en razones de lógica económica, las mismas se ven reforzadas por la idea de que 
los animales son de propiedad de la Pachamama, idea que se manifiesta en el ritual que precede al momento de la elección del animal que será sacrificado y en el acto mismo del sacrificio, el cual constituye un ritual en sî".

La edad de los camélidos sitúa la realización de todos los depósitos en agosto/septiembre, coincidiendo con la estación seca. Otros elementos, como los frutos silvestres y maíces que se incluyeron en las ofrendas, se encuentran frescos en la estación cálida, pero su disponibilidad y consumo fuera de esa época estarían mediados por el transporte en bultos (desde zonas valliserranas, $c a$. $100 \mathrm{~km}$ de distancia, al menos en el caso del chañar y la algarroba) y el almacenamiento, situación a la que se ha hecho referencia en otras oportunidades (Babot, 2011). Además, particularmente una parte de los endocarpos de chañar están representados en la forma de elementos perforados (cuentas o abalorios) más que como alimento.

De significación es también la ausencia de ciertas partes, tales como los miembros anteriores en todos los depósitos analizados, situación que registra Kessel \& Llanque Chana (2004) en oportunidad de las amparas, donde se reservan las extremidades delanteras de los camélidos nonatos o crías que fueron sacrificados años anteriores para ser empleados en rituales posteriores a manera de cucharas.

La ausencia de pupas de moscas, que afectan a las partes blandas animales en condiciones aerobias -las cuales se han registrado en otros contextos agropastoriles del área de estudio (Urquiza, 2010; Urquiza \& Aschero, 2014)-, indica que los elementos depositados fueron enterrados en el corto plazo, en coincidencia con la dinámica del acto de challar en pozos. Los indicadores de intemperismo registrados obedecen a la historia postdepositacional de los depósitos que incluye principalmente el tránsito: pisoteo sobre los materiales más próximos a la superficie y el colapso de los rellenos arqueológicos del muro del recinto E3 $\mathrm{y}$, en una menor medida, a la acción de roedores y carnívoros.

No obstante, el grado de incompletitud de los elementos óseos indicaría que los depósitos pudieron reabrirse para reanudar las ofrendas y volverse a cerrar de inmediato. La falta de un orden específico en tres de los contextos (Norte, Oeste y Sureste) se explicaría por la modalidad de colocación de las ofrendas, las que se arrojarían, a excepción del pozo Sur, en donde algunos materiales se recuperaron cuidadosamente dispuestos en torno al monolito o huanca central.

El pozo Sureste presenta una situación particular. Al parecer éste habría sido reabierto en sucesivas oportunidades. Esto se infiere de las elevadas señales de exposición a la intemperie, la ocurrencia de numerosos fragmentos óseos menores a 5 $\mathrm{cm}$ y la precipitación de carbonatos $\left(\mathrm{CO}_{3}\right)$ sobre la superficie de los huesos. Estos últimos serían consecuencia de que las lluvias/nieve podrían reaccionar con la arena hospedante o bien con los materiales/líquidos orgánicos del depósito, y movilizar carbonatos hasta su acumulación. Otros minerales blancos pulverizados serían parte de los elementos depositados intencionalmente en los pozos. A este respecto, Nielsen et al. (2017: 253) mencionan el uso de "whitestone", principalmente ceniza volcánica, que aparece en forma de cuentas y desechos de su manufactura, y minerales blancos pulverizados colocados en la tierra por aspersión como parte de las ofrendas en diferentes contextos andinos (i.e. apachetas, manantiales y cumbres de montañas).

Además, este rasgo presenta una morfología particular, puesto que se inicia como dos pozos o lóbulos contiguos que hacia la superficie confluyen en una única boca, lo que marca al menos dos momentos de uso diferenciados. El ordenamiento interno en el pozo Sureste es caótico sumando un indicador más de sucesivas remociones.

Un indicio adicional de la clausura de los depósitos está dada por la presencia de coprolitos de camélidos compactados en este pozo. Lecoq \& Fidel (2003) relatan el uso del guano de llama durante los rituales del marcaje en Potosí, Sur de Bolivia (señalada en la Puna argentina). Luego de haber finalizado la colocación de las ofrendas en el pozo, éste se cierra con la ayuda de una piedra plana (taquia), que se recubre de excrementos de llama. Nadie deberá abrir o tocar este receptáculo hasta el año siguiente para evitar la mala suerte. Por otro lado, en Kallawayas, en ocasión de un ritual que se ejecuta luego de las fiestas de carnaval, un cántaro que contiene varios elementos también se cubre con excrementos de ovejas y camélidos a los que se han cortado las orejas. En ambos casos, el guano actúa como un elemento de clausura del ritual. También el pozo Sur presenta signos de clausura, en este caso, mediante la aplicación de materiales arcillosos rojizos sobre la cima del monolito central. 
Finalmente, es preciso destacar que las recurrencias que hemos mencionado anteriormente en los casos estudiados (selección de lateralidad, presencia de un mismo número de individuos por conjunto, marcada estacionalidad, representatividad etaria y de partes de camélidos) son únicas en estos depósitos ya que no se verifican de la misma manera en otros contextos del área con presencia de restos de fauna de camélidos. No obstante, el depósito de individuos inmaduros en ofrenda (de Camelidae o bien, humanos) ha sido registrado anteriormente en ámbitos relacionados con lo sagrado (Cohen, 2005; Haber, 2006; Urquiza et al., 2013), al igual que otros elementos como la disposición de una roca central o huanca, el sellado o clausura de entierros y depósitos rituales, el uso de mezclas rojizas a modo de emplastos en la preparación del lugar, la delimitación o circunscripción espacial simple con piedras y la colocación de cuentas minerales, cordeles, chañar y algarrobo (Cohen, 2005; Haber, 2006; Gonzalez Baroni, 2013; Urquiza et al., 2013), que marcarían ciertas continuidades entre las prácticas votivas pasadas y presentes. Por otro lado, estos atributos no se encuentran representados en los conjuntos faunísticos contemporáneos asimilables al uso ordinario o doméstico de la fauna (e.g. Urquiza \& Aschero, 2014; Grant \& Escola, 2015).

\section{CONSIDERACIONES FINALES}

El emplazamiento de los conjuntos de objetos en el muro del recinto, su limitación por medio de piedras y la naturaleza y "potencia" de los elementos dispuestos en ellos que remiten a ciertas reglas o protocolos, permiten relacionar a los depósitos discretos y en pozos de E3 con instancias votivas de las sociedades agropastoriles puneñas. Por su parte, la cronología y el momento del año en que tuvieron lugar (agosto-septiembre), así como ciertas diferencias en el arreglo y contenido de los depósitos, proporcionan indicadores de su relación con dos circunstancias diferentes: el momento fundacional de E3 (pozo Sur) y posteriores celebraciones adscribibles a otras prácticas propiciatorias realizadas en la estación seca en los Andes Centro-Sur (pozo Sureste, depósitos Norte y Oeste) que acompañaron en el tiempo los sucesivos usos como corral y espacio de reunión, preparación y consumo de alimentos y artesanías del recinto (patio). Así lo documenta la dinámica de conformación del muro, que se fue integrando mediante estas prácticas a lo largo del tiempo, en lugar de corresponder a la erección única en un momento inicial de ocupación.

En todos los casos, la situación espacial de los depósitos remitiría a momentos de reunión del grupo de carácter público, eventualmente corresidente, debido a su localización en el muro perimetral y a la posición central del recinto E3 dentro del sitio. A este respecto apelamos a lo sostenido por Merlino \& Rabey $(1978,1983)$ acerca de que en la sacralidad de las sociedades agropastoriles de la Puna argentina no hay lugares que sean dedicados exclusivamente al culto, aunque sí algunos que se eligen expresa y sistemáticamente para ciertos rituales. Así, los challacos de la estación seca pueden llevarse adelante en ámbitos centrales dentro del recorrido pastoril (por ejemplo, una residencia principal) o destacados en el paisaje, a los cuales puede dirigirse el grupo expresamente, y en donde tanto el recorrido como la challa cumple una función demarcatoria del territorio familiar. De ellos participan la familia extensa y eventualmente los parientes rituales (compadres), siendo excepcionalmente colectivas. En Antofagasta de la Sierra pueden asumir el carácter de ritual semi-público en el que participan los parientes y vecinos en un número variable (García \& Rolandi, 2000). Asimismo, todos los sitios culturalmente significativos pueden alojar al acto ritual. De este modo, el patio y el corral constituyen verdaderos recintos sagrados y “(...) la casa misma es un lugar cúltico cuando se la está construyendo o en los retechados periódicos" (Merlino \& Rabey, 1983: 150).

La situación del pozo Sur, único con partes de camélido adulto y sin individuos crías con presencia de la lateralidad izquierda, es particular por su posición cardinal y alto grado de formalización, sumados a la presencia de un monolito de ignimbrita blanquecina central o huanca, asimilable a los mojones de cuarzo blanco descriptos por Merlino \& Rabey (1983). También lo particularizan la disposición de elementos en torno a él, además de la colocación de arcillas como revestimiento en las paredes y clausurando el evento. Le corresponde una redundancia de elementos artefactuales y no artefactuales ligados a la ofrenda y con "potencia" en los Andes, tanto en el pasado como en el presente: cuentas verdes completas, fallidas y sin terminar; mineral de cobre; palitos desbastados; algarrobo, 
chañar y maíz; cabello humano cortado, chimpa o flor de vellón, el uso del color rojo en distintas presentaciones sobre los objetos (sensu Agüero et al., 2001; Haber, 2006; Pimentel, 2013; entre otros) y restos carbonizados de plantas sahumadoras (Aguirre, 2012). Por su cronología coincidente con el inicio de la ocupación del recinto central, éste constituiría, al menos en su origen, un evento fundacional del espacio construido y habitado. A este respecto, apelamos a Arnold (2016) y Bugallo (2015) quienes sostienen una relación etimológica entre el vocablo corpachear (qurpachada) y el mojón (qurpa), elemento demarcatorio del territorio familiar y de los pastizales, denotando así el real alcance del rito.

Los demás depósitos darían cuenta de eventos votivos de otro tipo. Si bien podrían corresponderse con instancias de reparación de la vivienda o de habilitación de sus usos sucesivos, la época del año en la que se ubican, remiten claramente a un momento especial dentro de los ciclos anuales agropastoriles, particularmente, a la estación seca, oportunidad en la que actualmente, se devuelve a la Madre Tierra su generosidad y se le pide por el bienestar futuro (ver también Pimentel, 2009). La verificación de numerosas reglas seguidas en su conformación, indican la sacralidad de estas prácticas.

Los depósitos corresponderían a eventos de cierre rápido refrendados por la ausencia de entomofauna que requiere de condiciones aerobias para su reproducción. Por la ausencia de estratigrafía interna y la incompletitud de las piezas óseas se estima que habrían sido reabiertos en sucesivas oportunidades hasta su clausura final, apelando para ello en dos casos al guano de camélidos (Pozo Sureste) o emplastos rojizos (Pozo Sur). En el depósito Sur estas remociones se manifiestan en el formato del pozo por sus múltiples cubetas y en el importante grado de fractura de los restos óseos contenidos en él. La colocación de un cordel de dos colores o mishmido anudado (López Campeny, 2000), de mechones de cabello humano cortado, uno de ellos quemado, al igual que un fragmento de molar termoalterado, planchas de mica, palitos desbastados y aguzados coloreados de rojo-violáceo y el sahumado con plantas resinosas en un tiesto cerámico (ver referencia a este elemento en Merlino y Rabey, 1983), además de los propios restos carbonizados de plantas sahumadoras (Aguirre, 2012), formarían parte de los actos involucrados en su realización. La limpieza de los pisos que se observa en el recinto principal E3 (Aguirre et al., 2010) podría haber formado parte de esta etapa central en el año agropastoril, en concordancia con las prácticas actuales llevadas adelante en Antofagasta de la Sierra.

En estos casos, el sacrificio y la ofrenda de crías de camélidos o sullos en los depósitos constituiría un momento central de gran valor simbólico, dando cuenta de la reciprocidad o intercambio por los dones recibidos, al igual que el alimento compartido y la ofrenda de otros elementos de la cotidianeidad, a los que se sumarían rogativas. Así, el comensalismo habría formado parte importante de su realización. El volumen de alimento registrado parece indicar el consumo en un contexto de comidas en el hogar, no un festín público de grandes dimensiones. Distintas reglas implicadas en los dones ofrecidos y también en las ausencias, se refieren a instancias socialmente pautadas en las que, por ejemplo, el privilegio podríamos decir, se manifiesta en la colocación de lados derechos de las ofrendas animales (Cladera, 2010).

Los "pagos", "nidos de ofrenda y "coveros" cíclicos relacionados con diferentes demandas que implican gratitud (Fernández, 1994; Rösing, 1994; Núñez et al., 2017), quedarían ilustrados por éstos depósitos agropastoriles de la Puna sur argentina íntima e indisolublemente ligados a los ciclos de la vida cotidiana (Rösing, 1994: 197; Hastorf et al., 2001) durante el primer milenio de la era.

\section{AGRADECIMIENTOS}

Este trabajo se llevó a cabo en el marco de los proyectos PIP CONICET 577 (Dirs. C. Aschero y P. Babot), FONCyT PICT 2013-1703 (Dir. S. Hocsman) y PIUNT 26/G503 (Dirs. C. Aschero y P. Babot). Agradecemos a Lourdes Andugar, Ada Echevarría, Alejandra Molina, Mariana Dantas y Andrés Izeta por su colaboración; a A. Calisaya, G. Aguirre, S. Hocsman, L. Gonzalez Baroni y C. Cattáneo quienes participaron de la excavación de los depósitos de objetos; a las editoras del volumen, Dra. L. Miotti y Lic. E. García Añino, por su invitación a participar en él y a los revisores anónimos por sus comentarios. 


\section{REFERENCIAS}

Agüero, C.; Uribe, M.; Ayala, P.; Cases, B.\& Carrasco, C. 2001: Ceremonialismo del período Formativo en Quillagua, Norte Grande de Chile. Boletín de la Sociedad Chilena de Arqueología 32: 24-34.

Aguirre, M.G. 2012: Recursos vegetales: uso, consumo y producción en la puna meridional argentina (50001500 AP). Tesis Doctoral en Ciencias Naturales, Universidad Nacional de La Plata, La Plata.

Aguirre, M.G.; Babot, M.P.; Bajales, V.B. \& Olmos, A.V. 2010: Recursos vegetales post-aprovisionamiento en espacios domésticos agropastoriles de Antofagasta de la Sierra, Puna Meridional Argentina. Aplicación de la técnica de flotación. En: Bárcena, J.R. \& Chiavazza, H. (eds.): Actas del XVII Congreso Nacional de Arqueología Argentina, Tomo III: 1183-1186. Facultad de Filosofía y Letras, Universidad Nacional de Cuyo e Instituto de Ciencias Humanas, Sociales y Ambientales, CONICET. Mendoza.

Álvarez, M.; González, M.; Massigoge, A.; Kaufmann, C. \& Gutiérrez, M. 2010: La densidad mineral ósea y la variabilidad ontogénica en guanaco (Lama guanicoe). Implicancias para la construcción de marcos de referencia en Zooarqueología. In: De Nigris, M.E.; Fernández, P.M.; Giardina, M.; Gil, A.; Gutiérrez, M.A.; Izeta, A.; Neme, G. \& Yacobaccio, H.D. (eds.): Zooarqueología a principios del siglo XXI: Aportes teóricos, metodológicos y casos de estudio: 95-106. Libros del Espinillo, Buenos Aires.

Arnold, D.Y. 1991: House of Earth-Bricks and Inka Stones: Gender, Memory, and Cosmos. Qaqachaka. Journal of Latin American Lore 17(1-2): 3-69.

- 1998: Hacia un Orden Andino de las Cosas. Editorial Hisbol, La Paz.

- 2016: Territorios animados. Los ritos del señor de los animales como una base ética para el desarrollo productivo en los Andes. En: Román-López Dollinger, A.E. \& Galarza Mendoza, H.T. (eds.): Símbolos, desarrollo y espiritualidades. El papel de las subjetividades en la transformación social: 101-160. Instituto Técnico Ecuménico Andino de Teología (ISEAT), La Paz.

Avenburg, K. \& Martínez, B. 2014: Experiencias e interpretaciones en performances rituales (Iruya y el Cajón, noroeste argentino). Cuadernos de Antropología Social 39: 115-147.

BАвот, M.P. 2011: El primer milenio A.D. en la cuenca media del Río Las Pitas, Antofagasta de la Sierra, Catamarca. Aportes desde la historia ocupacional de la Estructura 3 del sitio Punta de la Peña 9, sector I. Ms.
- 2016: Notas sobre la arqueología de las plantas en un desierto de altura. Cadernos do Lepaarq. Textos de Antropologia, Arqueologia e Patrimônio. Dossier Archaeobotany in South America (R. Shceel-Ybert, org.) 13(25): 333-365.

Babot, M.P.; Aschero, C.A.; Hocsman, S.; Haros, M.C.; GonzÁlez Baroni, L.G. \& Urquiza, S.V. 2006: Ocupaciones agropastoriles en los sectores intermedios de Antofagasta de la Sierra (Catamarca): un análisis desde Punta de la Peña 9.I. Comechingonia. Revista de Arqueología 9: 57-78 (UNC).

Babot, M.P.; GonzÁlez Baroni, L.G.; Aguirre, M.G.; Calisaya, A.D.; Cattaneo, C. \& Hocsman, S. 2007: Rituales domésticos y depósitos de objetos en un recinto agropastoril de Punta de la Peña 9.I (Antofagasta de la Sierra). Serie Monográfica y Didáctica (FCN e IML) 46: 22.

B AKer, J. \& Brothwell, D. 1980: Animal Diseases in Archaeology. Academic Press Inc., London.

BARONE, R. 1987: Anatomie comparée des mammifères domestiques. Osteologie. Masson, París.

Behrensmeyer, A.K. 1978: Taphonomic and ecological information from bone weathering. Palaeobiology 4: $150-162$.

Benavente, A.; Adaro, L.; Gecele, P. \& Cunazza, C. 1993: Contribución a la determinación de especies animales en Arqueología: Familia Camelidae y Taruca del Norte. Serie Programas de Desarrollo, vol. 3. Universidad Nacional de Chile, Santiago.

Berenguer, J. 2004: Caravanas, Interacción y Cambio en el Desierto de Atacama. Sirawi Ediciones. Museo Chileno de Arte Precolombino.

Bermann, M. \& Estévez Castillo, J. 1995: Domestic Artifact Assemblages and Ritual Activities in the Bolivian Formative. Journal of Field Archaeology 22(4): 389-398.

Binford, L. 1981: Bones: Ancient Men and Modern Myths. Academic Press. New York.

Bugallo, L. 2015: Pachamama en fleur: modalités de relations et de productions à la puna de Jujuy (Argentine). Tesis Doctoral. École des hautes études en sciences sociales, Universidad de París, París.

Cladera, J. 2010: Continuidad y Cambio en las Prácticas Trashumantes. El caso de los ganaderos del Circuito Iscuya - Astilleros, Comunidad Kolla Finca Santiago (Provincia de Salta). KULA. Antropólogos del Atlántico Sur 3: 55-65.

Claps, L.E.; Debandi, G. \& Roig-Juñent, S. 2008: Biodiversidad de Artrópodos Argentinos, Vol. 2. Sociedad Entomológica Argentina ediciones, Imprenta Universidad Nacional de Tucumán. 
CoHen, M. 2005: Entre Guano y Arena... Ocupaciones Recurrentes: Un Caso de Estudio en el Sitio Punta de la Peña 9.III Antofagasta de la Sierra. Tesis de Licenciatura. Facultad de Ciencias Naturales e Instituto Miguel Lillo, Universidad Nacional de Tucumán.

Costa, M. \& KarasiK, G. 1996: ¿Supay o diablo? el carnaval en la Quebrada de Humahuaca (Jujuy, Argentina). En: Ross Cumrine, N. \& Schmetlz, B. (eds.): Estudios sobre el sincretismo en América Central y los Andes: 275-304. Colección Estudios Americanistas de Bonn.

Dean, E. \& KoJan, D. 2001: Ceremonial household and domestic temples: "Fuzzy" definitions in the Andean Formative. Kroeber Anthropological Society Papers 85: 110-135.

Dehouve, D. 2007: La ofrenda sacrificial entre los tlapanecos de Guerrero. Plaza y Valdés, CEMCA, UAG, México.

DrIEsCh, A. von den 1976: A Guide to the Measurement of Animal Bones from Archaeological Sites. Bulletin of the Peabody Museum of Archaeology and Ethnology No.1. Harvard University.

Driesche, R.D. van \& Bellows, T.S. 1996: Biological Control. Chapman \& Hall, New York.

Duviols, P. 1976: Un symbolisme Andin du double: le litomorphose de l'ancêtre. Actes du XLII Congrès des Américanistes, Tomo IV: 359-364. París.

FERNÁNDEZ, G. 1994: El banquete aymara: aspectos simbólicos de las mesas rituales aymaras. Revista Andina 12: $155-190$.

Fernández Gayubo, S. \& Pujade-Villar, J. 2015: Clase Insecta. Orden Hymenopera. Ibero Diversidad Entomológica@ccesible-SEA, n 59: 1-36.

Flores, G. \& Gómez, R. 2005: Taxonomía y biogeografía de cuatro especies de Psectrascelis (Coleoptera: Tenebrionidae) de la Precordillera y Cordillera de los Andes en Mendoza, Argentina. Revista de la Sociedad de Entomología Argentina 64(3): 93-106.

García, S.P. \& Rolandi, D.S. 2000: Relatos y ritual referidos a la Pachamama en Antofagasta de la Sierra, Puna meridional argentina. Relaciones de la Sociedad Argentina de Antropología 25: 7-25.

GIFForD, D.P. 1981: Taphonomy and paleoecology:a critical review of archaeology's sister disciplines. In: Schiffer, M. (ed.): Advances in Archaeological Method and Theory 4: 365-438.

GöBEL, B. 2000-2002: Identidades sociales y medio ambiente: la multiplicidad de los significados del espacio en la Puna de Atacama. Cuadernos del Instituto Nacional de Antropología y Pensamiento Latinoamericano 19: 267-296.
Gonzalez Baroni, L.G. 2013: Contextos funerarios y vida cotidiana en Antofagasta de la Sierra, Catamarca. Un enfoque desde la bioantropología, el emplazamiento y dinámica de los entierros (ca. 1500-1000 años AP). Tesis de grado de la Carrera de Arqueología, Universidad Nacional de Tucumán. Inédito.

Grant, J. \& Escola, P. 2015: La persistencia de un modo de producción doméstico durante el período Tardío: el caso de Corral Alto (Antofagasta de la Sierra, Argentina). Estudios Atacameños. Arqueología y Antropología Surandinas 51: 99-121.

GraYson, D. 1984: Quantitative Zooarchaeology. Academic Press, Orlando.

Gutiérrez, M.A. 2004: Análisis Tafonómicos en el Área Interserrana (Provincia de Buenos Aires). Tesis Doctoral. Universidad Nacional de La Plata. La Plata, Buenos Aires.

HABER, A.F. 2006: Una arqueología de los oasis puneños. Domesticidad, interacción e identidad en Antofalla, primer y segundo milenios d.C. Jorge Sarmiento Editor, Universitas Libros y Universidad del Cauca, Córdoba.

Hastorf, A.C.; Bandy, M.W.; Whitehead, T. \& SteadMAN, L. 2001: El periodo Formativo en Chiripa, Bolivia. Textos Antropológicos 13: 17-91.

Hinton, H.E. 1946: A New Classification of Insect Pupae. Proceedings of the Zoological Society of London 116: 282-328.

Hocsman, S. \& BАвот, M.P. 2018: La transición de cazadores-recolectores a sociedades agro-pastoriles en Antofagasta de la Sierra (Puna de Catamarca, Argentina): Perspectivas desde la agencia y las prácticas. Chungara, Revista de Antropología Chilena 50(1): 51-70.

Huchet, J.B.; Pereira, G.; Gomy, Y.; Keith Philips, T.; Alatorre-Bracamontes, C; Vásquez-Bolaños, M. \& Mansilla, J. 2013: Archaeoentomological study of a pre-Columbian funerary bundle (mortuary cave of Candelaria, Coahuila, Mexico). Annales de la Société Entomologique de France 49(3): 277-290. http://dx. doi.org/10.1080/00379271.2013.845474

IzETA, A.D. 2007: Zooarqueología del sur de los valles Calchaquíes (Provincias de Catamarca y Tucumán, República Argentina): Análisis de conjuntos faunísticos del primer milenio A.D. B.A.R. (International Series) S1612. John and Erica Hedges, Oxford.

Izeta, A.D.; Otaola, C. \& Gasco, A. 2009: Osteometría de falanges proximales de camélidos sudamericanos modernos. Variabilidad, estándares métricos y su importancia como conjunto comparativo para la interpretación de restos hallados en contextos arqueológicos. Revista del Museo de Antropología 2: 169-180. 
IzeTA, A.D.; Srur, M. \& Labarca Encina, R. 2012: Guía osteométrica de camélidos sudamericanos. $1^{\mathrm{a}}$ ed. Universidad Nacional de Córdoba.

KaUfmann, C.A. 2009: Estructura de edad y sexo en guanaco: estudios actualísticos y arqueológicos en Pampa y Patagonia. Sociedad Argentina de Antropología, Bs.As.

Kent, J.D. 1982: The Domestication and exploitation of the South American camelids: methods of analysis and their application to circum-lacustrine archaeological sites in Bolivia and Peru. Tesis Doctoral. Washington University, St. Louis, Missouri.

Kessel, J. van \& Llanque Chana, A. 2004: El Cuti o gran limpieza del ganado. En: van Kessel, J. \& Llanque, A. (eds.): Rituales agropastoriles de la Puna: 1-22. IECTA-Iquique, CIEDSA-Puno, Cuaderno de Investigación en Cultura y Tecnología Andina N No 7, Iquique.

LecoQ, P. \& Fidel, S. 2003: Prendas simbólicas de camélidos y ritos agro-pastorales en el sur de Bolivia. Textos Antropológicos 14: 7-54.

López CAMPENy, S. 2000: Tecnología, iconografía y ritual funerario. Tres dimensiones de análisis de los textiles formativos del sitio Punta de la Peña 9 (Antofagasta de la Sierra, Argentina). Estudios Atacameños 20: 29-65.

López Campeny, S.; Romano, A.S. \& Aschero, C.A. 2015: Remodelando el Formativo. Aportes para una discusión de los procesos locales en las comunidades agropastoriles tempranas de Antofagasta de la Sierra (Catamarca, Argentina). En: Korstanje, M.A.; Lazzari, M.; Basile, M.; Bugliani, F.; Lema, V.; Pereyra Domingorena, L. \& Quesada, M. (eds.): Crónicas materiales precolombinas. Arqueología de los primeros poblados del Noroeste argentino: 313-353. Sociedad Argentina de Antropología, Buenos Aires.

Loponte, D.M. 2004: Atlas osteológico de Blastocerus dichotomus (Ciervo de los pantanos). Editorial Los Argonautas, Buenos Aires.

Lyman, R. 1984: Bone Density and Differential Survivorship of Fossil Classes. Journal of Anthropological Archaeology 3: 259-299.

- 1994: Vertebrate Taphonomy. Cambridge Manuals in Archaeology. Cambridge University Press, Cambridge.

Mengoni Goñalons, G.L. 1988: Análisis de Materiales Faunísticos de Sitios Arqueológicos. Xama 1: 71-120.

- 1999: Cazadores de guanacos de la estepa patagónica. Sociedad Argentina de Antropología, Buenos Aires.

Menegaz, A.N. 2000: Los camélidos y cérvidos del cuaternario del sector bonaerense de la región pampeana. Tesis Doctoral. Facultad de Ciencias Naturales y Museo, Universidad Nacional de La Plata.
Merlino, R.J. \& Rabey, M. 1978: El ciclo agrario-ritual en la Puna Argentina. Relaciones de la Sociedad Argentina de Antropología 12: 47-70.

- 1983: Pastores del Altiplano Andino Meridional: religiosidad, territorio y equilibrio ecológico. Allpanchis 21: 149-171.

Mondini, N.M. 2003: Formación del Registro Arqueofaunístico en Abrigos Rocosos de la Puna Argentina. Tafonomía de carnívoros. Tesis Doctoral. Universidad de Buenos Aires, Buenos Aires.

Munsell Geologicl Rock- Color Chart. 2009 (Revised 2011): Produced by Munsell Color. Grand Rapid, MI.

Nicholson, R. 1993: A morphological investigation of burnt animal bone and an evaluation of its utility in archaeology. Journal of Archaeological Science 20: 411-428.

Nielsen, A.E. 2006: Celebrando con los antepasados. Arqueología del espacio público en Los Amarillos, Quebrada de Humahuaca, Jujuy, Argentina. Malku Ediciones, Buenos Aires.

Nielsen, A.; Angiorama, C. \& Ávila, F. 2017: Ritual as Interaction with Non-Humans: Prehispanic Mountain Pass Shrines in the Southern Andes. In: Rosenfeld, S.A. \& Bautista, S.L. (eds.): Rituals of the past: prehispanic and colonial case studies in Andean archaeology: 241-266. University Press of Colorado.

Núñez, L.; Cartajena, I.; Carrasco, C.; LóPez, P.M.; De Souza, P.; Rivera, F. \& Santander, B.D. 2017: Presencia de un Centro Ceremonial Formativo en la Circumpuna de Atacama. Chungara, Revista de Antropología Chilena 49(1): 3-33.

OliverA, D.E. 1988: La opción productiva: apuntes para el análisis de sistemas adaptativos del Período Formativo del NOA. Precirculados de las ponencias científicas del IX Congreso Nacional de Arqueología Argentina: 83-101. Instituto de Ciencias Antropológicas, UBA, Buenos Aires.

- 1998: Cazadores y pastores tempranos de la Puna Argentina. In: Past and Present in Andean Prehistory and Early History. Etnologiska Studier 42: 153-180.

Pacheco Torres, V.R.; Altamirano Enciso, A. \& Guerra Porras, E. 1979: Guía Osteológica para camélidos sudamericanos. Serie Investigaciones 4. Departamento Académico de Ciencias Histórico-Sociales, Universidad Mayor de San Marcos, Lima.

Pazzarelli, F. 2014: Tistincha para la Pachamama. Cuando masticar no es humano. Ponencia presentada al II Seminario de Estudios Andinos no Brasil. II Seminário de Estudos Andinos no Brasil.

PIEK, T. 1985: Insect venoms and toxins. In: Kerkut, G.A. \& Gilbert, L.I. (eds): Comprehensive insect physiol- 
ogy, biochemistry and pharmacology: 595-633. Vol. 11. Pergamon Press, Oxford.

Pimentel, G. 2009: Las huacas del tráfico: Arquitectura ceremonial en rutas prehispánicas del desierto de Atacama. Boletín del Museo Chileno de Arte Precolombino 14(2): 9-38.

- 2013: Redes viales prehispánicas en el desierto de Atacama. Viajeros, movilidad e intercambio. Tesis de Doctorado en Antropología, mención Arqueología, Universidad Católica del Norte y Universidad de Tarapacá, San Pedro de Atacama, Chile.

Podjacer, A. \& Mennelli, Y. 2009: «La Mamita y Pachamama» En: Las Performances de Carnaval y la Fiesta de Nuestra Señora de la Candelaria en Puno y en Humahuaca. Cuadernos FHyCS-UNJu 36: 69-92.

ReITZ, E.J. \& WING, E.S. 1999: Zooarchaeology. Cambridge Manuals in Archaeology. Cambridge University Press, Cambridge.

Roig-Juñent, S.; Claps, L.E. \& Morrone, J.J. 2014: Biodiversidad de Artrópodos Argentinos 4. Editorial INSUE - UNT, San Miguel de Tucumán.

RösING, I. 1994: La deuda de ofrenda: un concepto central de la religión andina. Revista Andina 12(1): 191216.

Salemme, M.; Miotti, L. \& Tonni, E. 1988: La determinación sistemática de los mamíferos en el análisis arqueofaunístico. En: Ratto, N. \& Haber, A. (eds.): De Procesos, Contextos y Otros Huesos: 65-73. UBA, Buenos Aires.

Silverman, H. 2004: Andean Archaeology. Blackwell Publishing, Malden, Massachusetts.

Symmons, R. 2002: Bone Density Variation between Similar Animals and Density Variation in Early Life: Implications for Future Taphonomic Analysis. In: O’Connor, T. (ed.): Biosphere to Lithosphere: 86-93. Oxford Books, Oxford.
URQUIZA, S.V. 2010: Entomología y Química en el contexto arqueológico: Nuevos elementos para el entendimiento de la historia tafonómica del registro arqueofaunístico en Antofagasta de la Sierra, Catamarca. En: De Nigris, M.; Fernández, P.M.; Giardina, M.; Gil, V.; Gutiérrez, M.A.; Izeta, A.; Neme, G. \& Yacobaccio, H.D. (eds.): Zooarqueología a principios de siglo XXI: aportes teóricos, metodológicos y casos de estudio: 429-438. Ediciones del Espinillo, Buenos Aires.

Urquiza, S.V. \& Aschero, C.A. 2014: Economía animal a lo largo del Holoceno en la Puna Austral Argentina: Alero Punta de la Peña 4. Cuadernos del Instituto Nacional de Antropología y Pensamiento Latinoamericano. Series Especiales 2(1): 86-112.

Urquiza, S.v.; Romano, A.s. \& López Campeny, S.M. 2013: Historia Ocupacional y Prácticas Sociales: un análisis arqueofaunístico contextual. Sitio Piedra Horadada 2, Antofagasta de la Sierra, Catamarca, Argentina. En: Izeta, A.D. \& Mengoni Goñalons, G.L. (eds.): De la Puna a las Sierras Avances y Perspectivas en Zooarqueología Andina: 121-145. British Archaeological Research, Oxford.

VARGAS, H. 2006: Descripción de la larva de último instar y de la pupa de Cryptophlebia cortesi Clarke (Lepidoptera: Tortricidae). Neotropical Entomology 35(3):338-343.

- 2007. Larva de último instar, pupa y nuevo registro de distribución de Periploca otrebla Vargas (Lepidoptera: Cosmopterigidae). Neotropical Entomology 36(6): 894-901.

WheELER, J.C. 1982: Aging llamas and alpacas by their teeth. Llama World 1: 12-17.

- 1999: Patrones prehistóricos de utilización de los camélidos sudamericanos. Boletín de Arqueología PUCP 3: 297- 305. 
